\title{
Significant production improvement using optimization of completion and artificial lift: case studies from South-West Iran
}

\author{
Rahman Ashena ${ }^{1}$ (D) Mahmood Bataee ${ }^{2} \cdot$ Hamed Jafarpour $^{3} \cdot$ Hamid Abbasi $^{3} \cdot$ Anatoly Zolotukhin $^{4}$. \\ Mohammad Mirhashemi ${ }^{5}$
}

Received: 6 July 2020 / Accepted: 17 November 2020 / Published online: 29 November 2020

(c) The Author(s) 2020

\begin{abstract}
Productivity of wells in South-West Iran has decreased due to completion and production problems in recent decades. This is a large risk against sustainable production from the fields. To allow stable production, an important measure is completion and production optimization including artificial lift methods. This was investigated using simulations validated by pilot field tests. Several case studies were considered in terms of their completion and production. Five scenarios were investigated: natural production through annulus and tubing (scenario-1 and 2), artificial gas lift production through annulus (scenario-3), through tubing using non-standard gas lift (scenario-4) and using standard gas lift (scenario-5). Scenario-1 is currently the case in most wells of the field. To find the optimal scenario and completion/production parameters, simulations of 11 wells of an oilfield in the region were carried out using nodal and sensitivity analysis. The optimized parameters include wellhead pressures (WHPs), tubing dimensions, maximum tolerable water cuts and gas oil ratios and artificial gas injection rate. Simulation results were validated by pilot field tests. In addition, appropriately selected wellhead and Christmas trees for all scenarios were depicted. Simulations confirmed by field pilot tests showed that optimization of completion and production mode and parameters can contribute largely to production improvement. The results showed that the current scenario-1 is the worst of all. However, production through tubing (scenario-2) is optimal for wells which can produce with natural reservoir pressure, with an increase of $800 \mathrm{STB} /$ Day rate per well compared with scenario-1. However, for wells requiring artificial gas lift, the average production rate increase (per well) from the annulus to tubing production was 1185 STB/Day. Next, using the standard gas lift (scenario-5) was found to be the optimal mode of gas lifting and is strongly recommended. WHPs in scenario-5 were the greatest of all, whereas scenario-1 gave the lowest WHPs. The optimal tubing diameter and length were determined. The greatest maximum tolerable water cut was obtained using scenario-5, whereas the lowest was with scenario-1. The maximum tolerable GOR was around $1900 \mathrm{scf} / \mathrm{STB}$. Changing of scenarios did not have significant effect on maximum tolerable GOR. The optimal artificial gas injection rates were found. This validated simulation work proved that completion and production optimization of mode and parameters had considerable contribution to production improvement in South-West Iran. This sequential comprehensive work can be applied in any other field or region.
\end{abstract}

Keywords Production parameters optimization · Completion optimization · Artificial lift · Gas lift · Wellhead selection

\section{Introduction}

Rahman Ashena

ashena.rahman@gmail.com

1 Asia Pacific University of Technology and Innovation (APU), Kuala Lumpur, Malaysia

2 Curtin University, Miri, Malaysia

3 Shiraz University, Shiraz, Iran

4 Gubkin Russian State University (NRU) of Oil and Gas, Moscow, Russia

5 Azad University of Science and Research, Tehran, Iran
Anglo-Persian Oil Company (which changed named to BP in 1955) completed wells drilled in South-West (SW) of Iran such that their production was through the production casing (i.e., no use of completion string in the well). After several decades of production, they modified their procedure by running simple completion strings without packers, and oil was produced through the annulus (between the completion string and the production casing). This production mode from Asmari reservoir formation was justified until the 
1990s because of dramatically high production rates of wells (typically 5-15 K-STB/Day) in the region. Although production rates have declined dramatically in the last $20-30$ years, this traditional mode was still practiced in the region for decades (from initial production till the 2010s). This has several consequences: After decades of production, due to this inappropriate mode of completion/production and also ignorance in optimization, natural oil production declined to very low rates or zero in many wells. Next, prolonged reservoir formation depletion and formation damage have caused reduction of reservoir oil zone thickness to low values, putting wells at risk of water and gas conning. Finally, it caused corrosion and mechanical damage to production casing which caused well integrity issues necessitating production halts for workover operations. Overall, these issues have reduced productivity of wells and jeopardized sustainable production from the fields.

Following occurrence of the aforementioned issues, the operator has recently proceeded to several measures to take conditions of existing wells under control and allow sustainable production. These consist of:

Stimulation: When production impairment is due to the reservoir rock or its damage, stimulation may effectively solve the problem. Some stimulation methods have been recently devised which include engineering design of acid batch compositions and stages (see an example in Jafarpour et al. 2021); hydraulic fracturing, radial jet drilling (RJD) of existing wells (see Ashena et al. 2020), etc. These are implemented via rig-less coiled tubing or rigbased workover jobs. Application of horizontal drilling in currently thin Asmari reservoir is recently considered as a stimulation method to contribute to productivity of wells. Some of these stimulation jobs need workover rigs (such as horizontal drilling) and the others need coiled tubing units. Therefore, these are costly options.

Completion and production optimization: When production impairment is due to inappropriate completion and production mode or parameters, their optimization can be really effective. Because of already ignoring this important work, this method can efficiently improve production from SW, Iran fields. It is also more cost-effective in improving well productivity compared to stimulation practices. This is because most of optimization measures can be implemented without a need for a costly workover job. Therefore, the operator has recently started modifying and improving its previous traditional completion and production modes and parameters.

Coroner (1995) showed that definition of the reservoir flow mechanism, optimized perforating schemes, enhanced carbonate stimulation and improved completion designs contributed to success in production rate from a heavy oil field. Wang (2003) comprehensively discussed and compared several optimization techniques including nodal analysis and optimizing algorithms which can apply to production. Pontiff and Boyer (2005) discussed a method called Process Optimization Review to be used in production operations for identification of opportunities to increase profitability while reducing greenhouse gases such as methane. Nasser et al. (2012) discussed using a statistical failure analysis method to evaluate performance of downhole pumps to extend the equipment lift time and reduce workover costs. Shere et al. (2008) developed an online production optimization which allowed users to further analyze problems with wells by downloading the models and running them offline.

This work is devoted to a comprehensive discussion on completion and production optimization of several wells in SW, Iran. Few works in the literature have been done in this region. These include Shadizadeh and Zoveidavianpour (2009) and Azin et al. $(2014,2019)$ each of which was merely a production optimization work on only one single well. In addition, a very sequential and practical approach is given for production optimization of an oilfield which is hardly found in the literature. This approach can be applied to any other field or region.

The objectives of optimization in this work are great enough production rates (while being below maximum allowable rate), high enough surface wellhead pressure and high enough tolerable water cuts and gas oil ratios (GORs). Great enough production rates guarantee economic production from the well; high enough WHP is required to push produced oil to reach a manifold/refinery; high tolerable water cuts and gas oil ratios (GORs) allow sustained production before these water cuts and GORs are reached.

In this work, first, setting an upper limit for production rate is considered as an important measure to prevent conning. Using reservoir engineering models and experience, a maximum permissible production rate of 1500-3000 STB/ Day (preferentially fixed at 1500 STB/Day) is determined in the studied field. The maximum allowable rate differs depending on the location/placement of the well in the reservoir and its conditions.

Next, using a multiphase flow simulator (PIPESIM), simulation of production from 11 wells and optimization of their completion and production are re-considered with the purpose of comparing different production parameters and scenarios (including artificial lift) and finding the optimal one. Simulation of one of the wells is presented step-by-step. To achieve this, first the best-matching multiphase flow correlation is found. Next, the current production conditions are simulated and compared with the actual one. Next, it is necessary to find optimized completion string dimensions (diameter and length) because, in case of any upcoming workover jobs, current tubing strings can 
be replaced with ones with optimized dimensions. The other optimized parameters include wellhead pressures (WHPs), maximum tolerable water cuts and gas oil ratios (GORs) and artificial gas injection rates.

There are five completion/production modes or scenarios to be considered for optimization. The scenarios consist of:

1. Natural production through the annulus of tubing-casing (traditional production mode),

2. Natural production through the tubing,

3. Artificial gas lift-assisted production through the annulus,

4. Artificial gas lift production (non-standard) through the tubing, and

Artificial gas lift (standard) in which production occurs through the tubing.

Next, pilot test results for the second case study well are presented and compared with simulations briefly, which are used for verification/validation of the simulation results.

Finally, the summary results of all the studied 11 wells in G. oilfield located in SW Iran are graphically presented and the optimal production scenarios and parameters are determined for implementation in the whole field.

Ann essential part of any shift in completion or production scenario is using an appropriate wellhead and Christmas tree selection. Therefore, different types of Christmas trees are discussed for each scenario, and requirements for shift from one Christmas tree to another are also discussed.

\section{Field of study}

The investigated onshore oilfield is located in South West Iran (see Fig. 1). The G. oilfield which is investigated in this study had an initial oil in place of 39 billion barrels with natural flow recovery factor of $19 \%$. The recovery factor can be definitely increased using artificial lift methods and enhanced oil recovery methods.

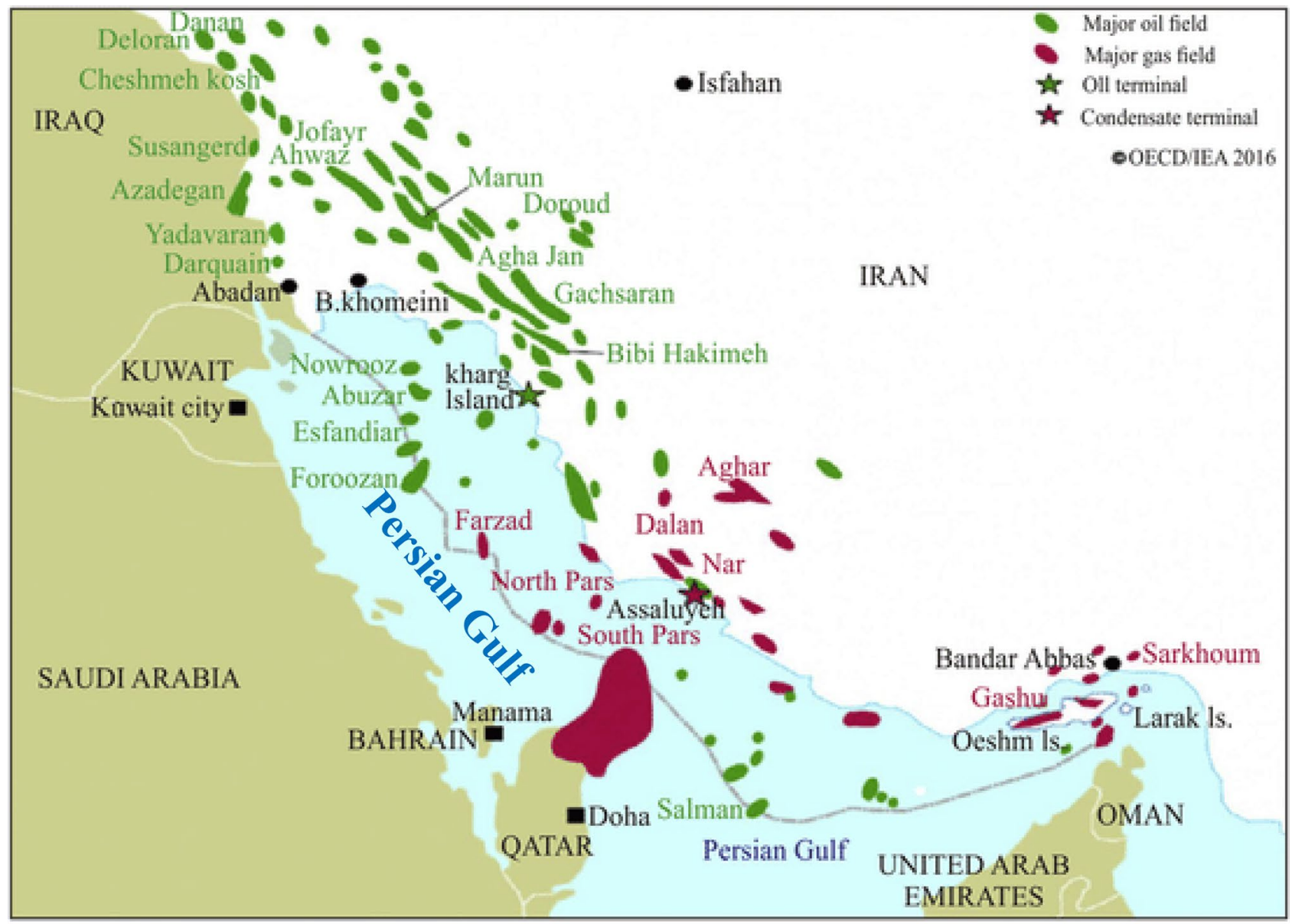

Fig. 1 Location of the studied onshore field in SW, Iran (Hunter 1921) 
The reservoir formation for the studied wells in this field is Asmari carbonate formation. The carbonate formation is composed of limestone, partly dolomitized and is highly fractured. The production drive mechanism in this field is mostly gas-cap drive, with some drive from the water zone as well. In 1908, the first well was drilled and produced from Asmari formation in the Masjed Soleyman (MIS), SW Iran. Therefore, Asmari reservoir formation has been depleted for more than 110 years and is considered a low-pressure reservoir. However, in the studied field, production from the Asmari reservoir started earlier in 1930.

\section{Case study I}

This is the first studied case study well. Following multiphase flow correlation matching, simulation of the current production conditions (production through the annulus) is considered and its production parameters are found and compared with the actual. Next, optimal tubing dimensions (diameter and length) are determined which are important parameters to be replaced in a future workover job. Next, maximum allowable water cut and gas oil ratio (GOR) are determined. Then, production conditions through annulus and tubing are compared and the optimal production scenario is found. Next, the role of artificial gas lift in improving well performance and parameters is investigated. It is noted that, in order to prevent conning issues, the maximum production rate of $1500 \mathrm{STB} / \mathrm{Day}$
Fig. 2 Well schematic and dimensions (Case study I)

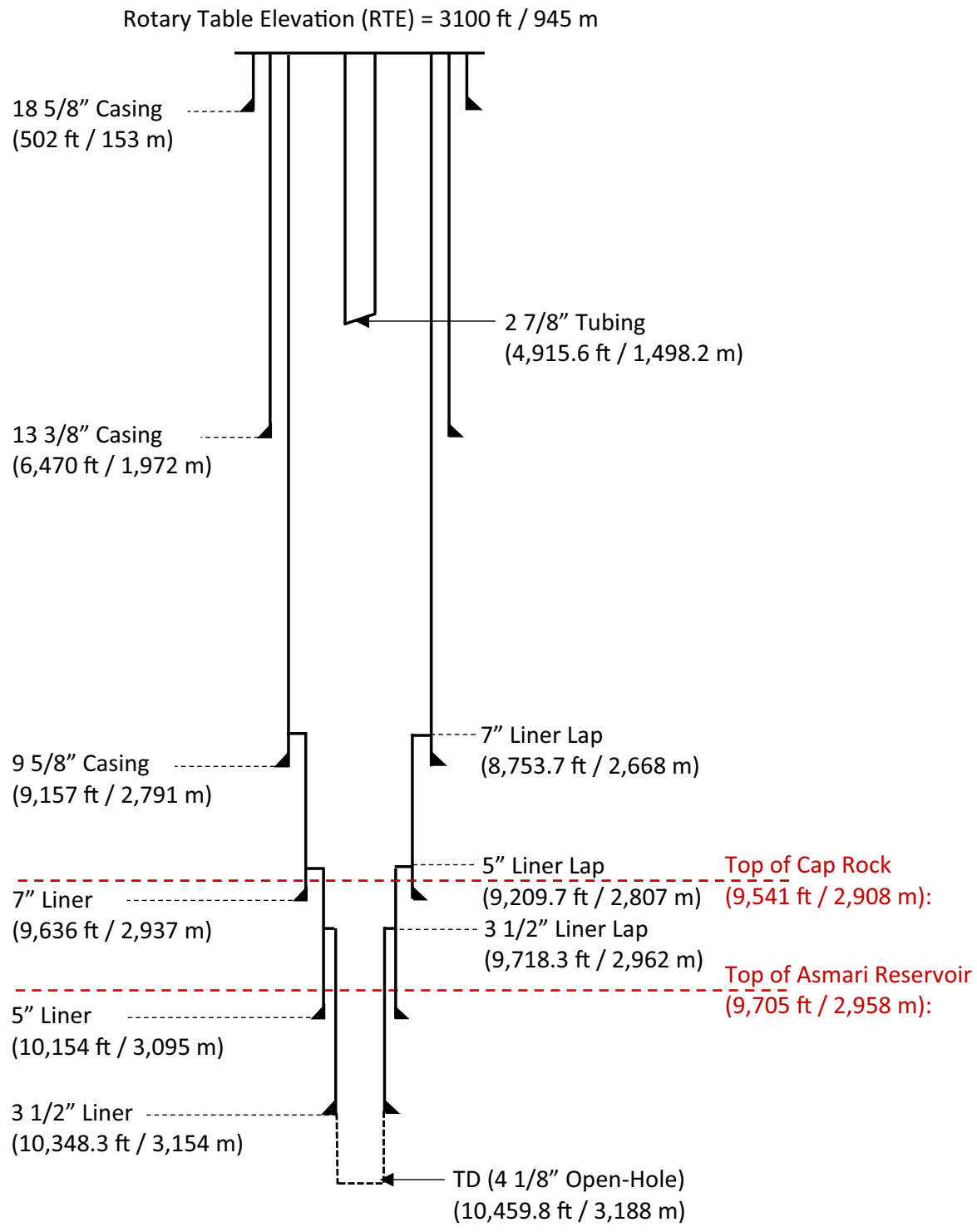


Table 1 Well and reservoir pressure data

\begin{tabular}{ll}
\hline Parameter & Value \\
\hline $\begin{array}{l}\text { Gas zone pressure at datum for gas }(656 \mathrm{ft} / 200 \mathrm{~m} \text { below mean sea level, } \\
\text { MSL): }\end{array}$ & $1920 \mathrm{psi}$ \\
Oil zone pressure at datum $(5085 \mathrm{ft} / 1550 \mathrm{~m}$ below MSL) & $2128 \mathrm{psi}$ \\
Water zone pressure at $9000 \mathrm{ft} / 2743 \mathrm{~m}$ below MSL: & $2953 \mathrm{psi}$ \\
Gas pressure gradient: & $0.057 \mathrm{psi} / \mathrm{ft}$ \\
Oil pressure gradient: & $0.33 \mathrm{psi} / \mathrm{ft}$ \\
Water pressure gradient: & $0.48 \mathrm{psi} / \mathrm{ft}$ \\
Gas Oil Contact (GOC): & $7087 \mathrm{ft} / 2160 \mathrm{~m}$ below MSL \\
Water Oil Contact (WOC): & $7448 \mathrm{ft} / 2270 \mathrm{~m}$ below MSL \\
\hline
\end{tabular}

was recommended for this well (by reservoir engineering department). Finally, appropriate wellhead and Christmas tree for the new completion and improved well performance are recommended.

\section{Input data}

Figure 2 shows the studied well schematic and dimensions including casings and tubing information. Table 1 shows pressure data and gas-oil and water-oil contact depths. Table 2 shows final input data required for simulation consisting of well schematic data, reservoir fluid properties, production data and reservoir formation pressure.

\section{Multiphase flow correlation selection}

Having created a base model using the input data entered into a multi-phase simulator (PIPESIM), it is important to select an optimal multiphase flow correlation for flow and pressure drop predictions. For calculation of fluid pressure drop within the reservoir rock, there are several equations. In this work Vogel's equation has been considered (Vogel 1968). For calculation of pressure drops in the wellbore (from the bottomhole to the surface wellhead), there are several correlations. It is necessary to find the best-matching one with measured flowing pressure data which are inserted into the simulator. Production path in the studied wells is set through the annulus. As the pressure measuring device cannot run inside the annulus, but run through the tubing, no pressure data can be recorded in the annulus. Therefore, the only available measured data would inside the casing and at the surface (wellhead). Next, different multiphase flow correlations are selected to be plotted. They consist of Lokhart and Martinelli (1949), Duns and Ross (1963), Hagedorn and Brown (1965), Beggs and Brill (1973), Mukhrejee and Brill (1985), Ansari (1989). Therefore, it is possible to compare them and recognize which one fits the most with the data. This is done visually or using a statistical error function, which is usually root mean square error (RMSE). Figure 3 shows that Hagedorn and Brown (HBR) correlation shows the best matching with measured data.

\section{Simulation of current production conditions}

Simulation of current production conditions of the first case study well was performed using nodal analysis. Nodal analysis procedure consists of selecting a division point or node in the well (here bottomhole) and dividing the system at this point (Beggs 2003). Its application to well production systems was first proposed by Gilbert (1954) and discussed
Table 2 Used information in constructing the multiphase model for case study I

\begin{tabular}{ll}
\hline Parameter & Value \\
\hline Bottomhole measured depth (depth of reservoir top): & $10,348.2 \mathrm{ft} / 3154 \mathrm{~m}$ \\
Bottomhole pressure (static pressure at top of reservoir): & $2655 \mathrm{psi}$ \\
Bottomhole temperature (static temperature at reservoir top): & $145^{\circ} \mathrm{F}\left(62.7^{\circ} \mathrm{C}\right)$ \\
Flowing wellhead pressure (WHP): & $160 \mathrm{psi}$ \\
Production flow rate (Q): & $1000-1500 \mathrm{STB} / \mathrm{Day}$ \\
Productivity index (estimated): & $77 \mathrm{STB} / \mathrm{Day} / \mathrm{psi}$ \\
API degree (of stock-tank oil): & 30 \\
Water cut (current value): & zero \\
Gas oil ratio (GOR): & $580 \mathrm{scf} / \mathrm{STB}$ \\
(Formation) gas specific gravity (with respect to air): & 0.64 \\
(Formation) water specific gravity (with respect to fresh water): & 1.02 \\
\hline
\end{tabular}




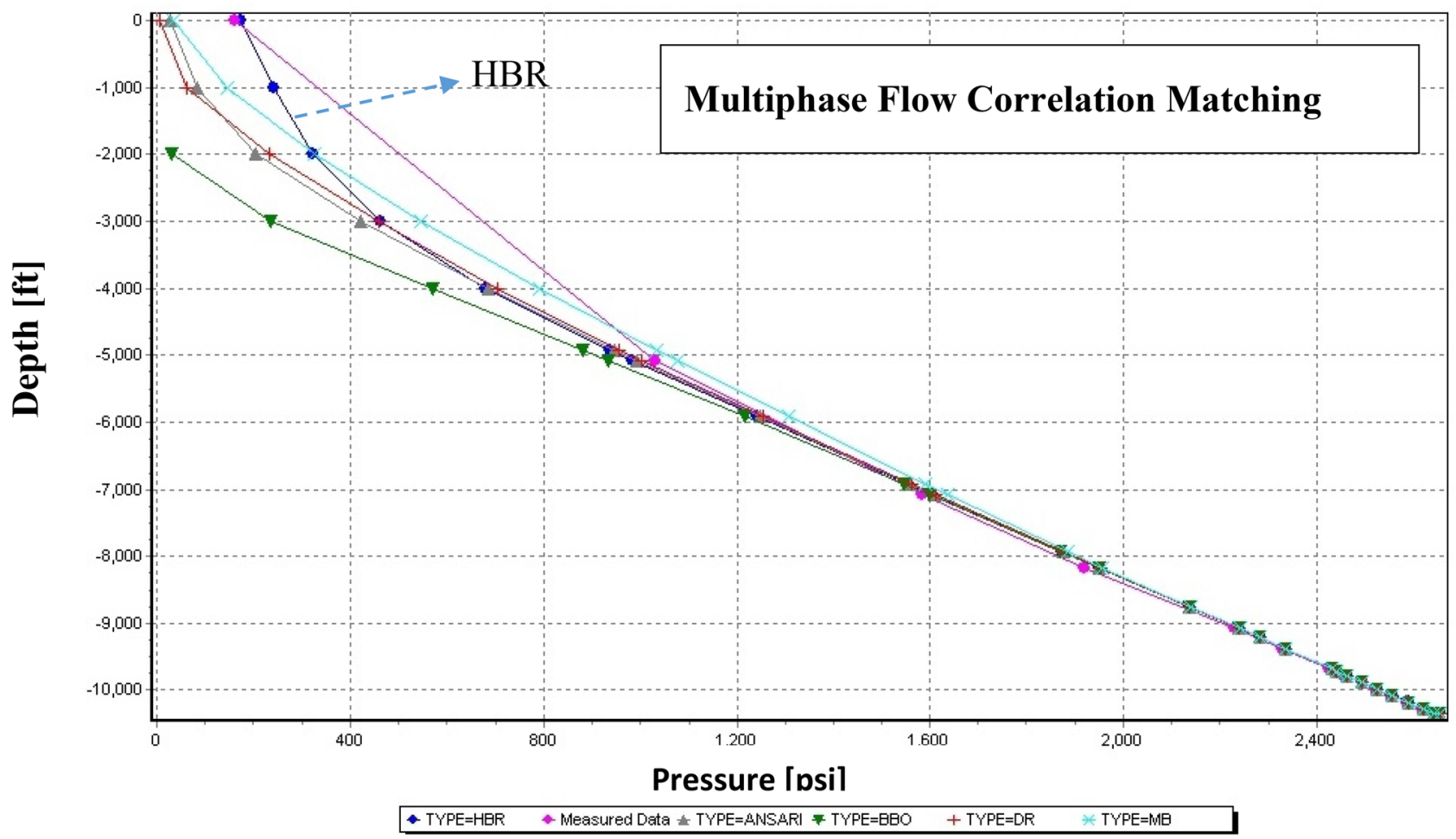

Fig. 3 Different multiphase flow correlations vs. measured flowing pressure data. Hagedorn and Brown (HBR, in dark blue) shows the best fitting with measured data

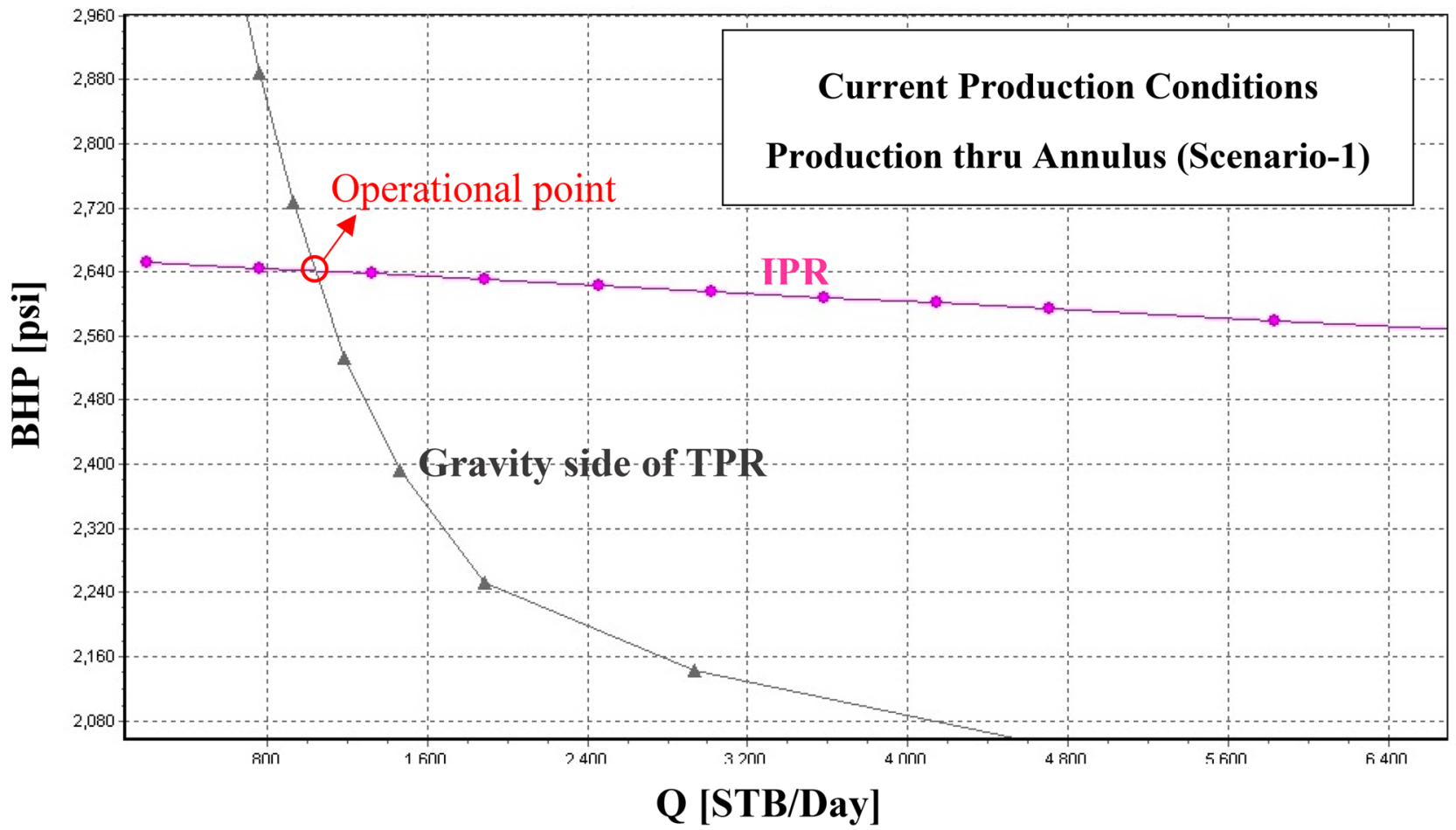

Fig. 4 Simulation of current production for case study well\#1. Production rate $(\mathrm{Q})$ is $1048 \mathrm{STB} /$ Day with bottomhole pressure (BHP) of 2640 psig. "IPR" stands for Inflow Performance Relationship. "BHP" stands for bottomhole pressure. "TPR" stands for Tubing Per- formance Relationship. For clarity, only the declining side of the TPR which pertains to its gravity is shown, but the ascending side of the TPR (which pertains to friction) was NOT shown 
by Nind (1964) and Brown and Beggs (1978), and later by Dmour (2013) and Soleimani (2017).

Production was done through the annulus (scenario-1). Figure 4 shows that the well produces with the production rate (Q) of 1048 STB/Day and bottomhole pressure (BHP) of 2640 psig at the selected wellhead pressure (WHP) of 160 psig. It is noted that the minimum WHP required in this well for natural production is 150 psi. Below this WHP, oil cannot reach the manifold before it is pressurized to reach the refinery. Therefore, completion and production optimization is required so that production can be possible at a reasonably high WHP.

The operational point is the intersection of the inflow performance relationship (IPR) curve and tubing performance relationship (TPR) curve. As the well produces from the annulus with the actual production flow rate is around $1000 \mathrm{STB} /$ Day, the operational point which is located on the declining side of the TPR (which pertains to gravity) confirms the actual case. The ascending side of TPR which pertains to friction also potentially intersects with the IPR, but it would result in extremely high production rates (of around $20,000 \mathrm{STB} / \mathrm{Day})$. This extremely great rate is beyond the capacity of the reservoir formation (otherwise, a gas or water conning problem would quickly occur). For better clarity of the figure, the ascending side of TPR which pertains to friction was NOT shown.

\section{Optimization of tubing dimensions}

Before the case study well underwent a workover operations, its dimensions (diameter and length) are optimized. Optimization of these dimensions was done for two cases of natural production through the annulus and tubing (i.e., scenarios 1 and 2). The tubing length was considered constant $(4921 \mathrm{ft} / 1500 \mathrm{~m})$. The selected wellhead pressure was 160 psig.

\section{Tubing diameter size}

Tubing diameter optimization and selection are accomplished using two methods of nodal analysis and sensitivity analysis:

In production through the annulus, results of nodal analysis simulation (Fig. 5) show that the optimal diameter size is $27 / 8$ " (gray color) because it gives the greatest production rate of all (1250 STB/Day). In scenario-2, results of nodal analysis simulation (Fig. 6) show that using $3 \frac{1 / 2}{2}$ and $4 \frac{1 / 2}{2}$ " tubing, production rates of 1900 STB/Day and 6200 STB/ Day can be obtained, respectively. The rate of 6200 STB/ Day is extremely high for the reservoir, which would shortly cause gas and water conning during production. However, by increasing wellhead pressure (WHP), it would be possible to limit the production rate below the maximum allowable one (here, 1500 STB/Day). Therefore, either $31 \frac{1}{2}$ " and $41 \frac{1}{2}$ "
Fig. 5 Comparison of different tubing sizes in production through the annulus. In annulus production, points of intersection of declining/gravity side of TPR with IPR must be considered as operational points. In the simulation, tubing length was considered constant $(4921 \mathrm{ft} / 1500 \mathrm{~m})$. The selected wellhead pressure was $160 \mathrm{psig}$. The results of simulation show the optimal diameter size is 2 $7 / 8$ "

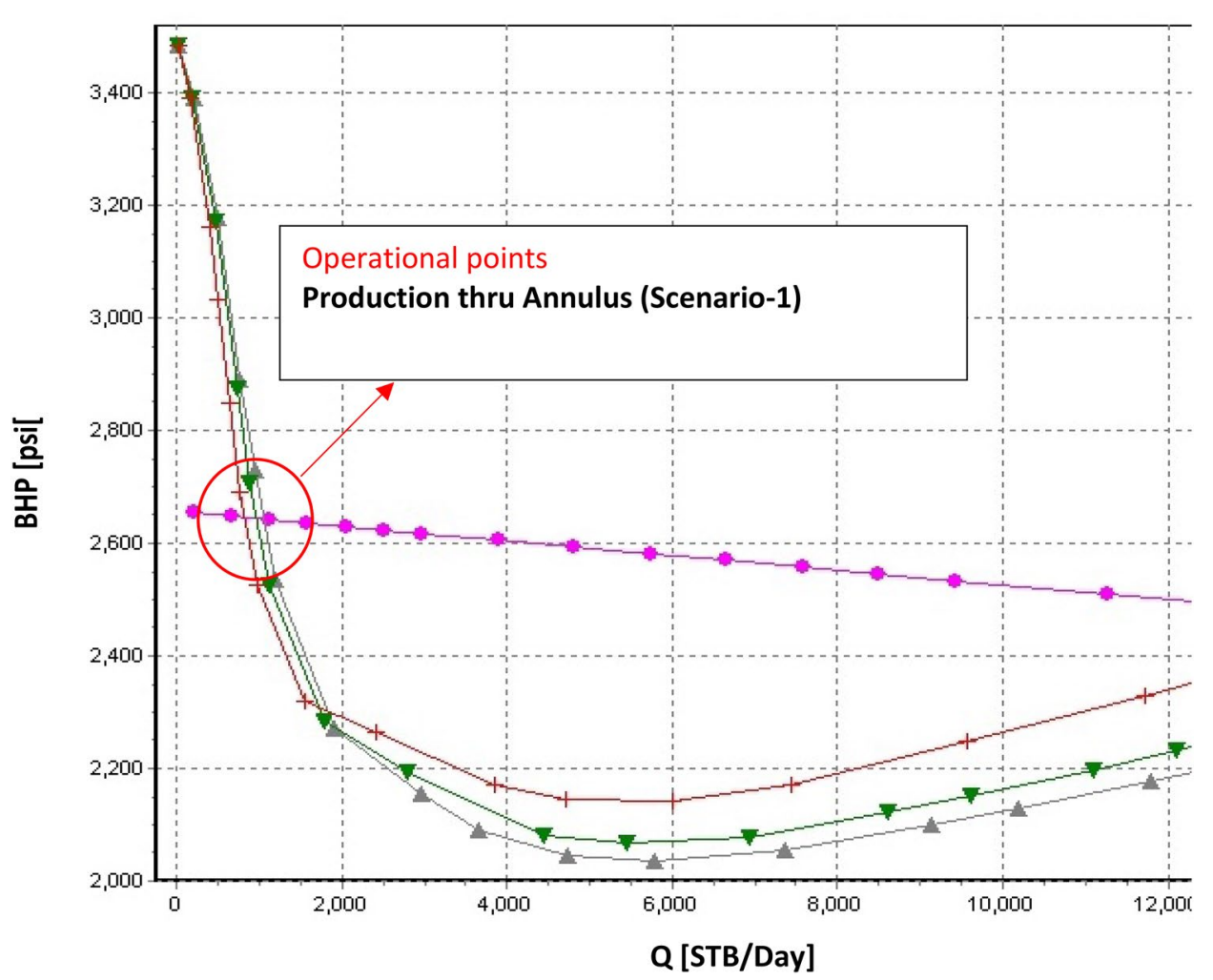

Q [STB/Day]

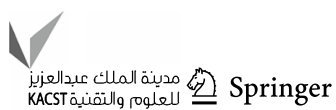




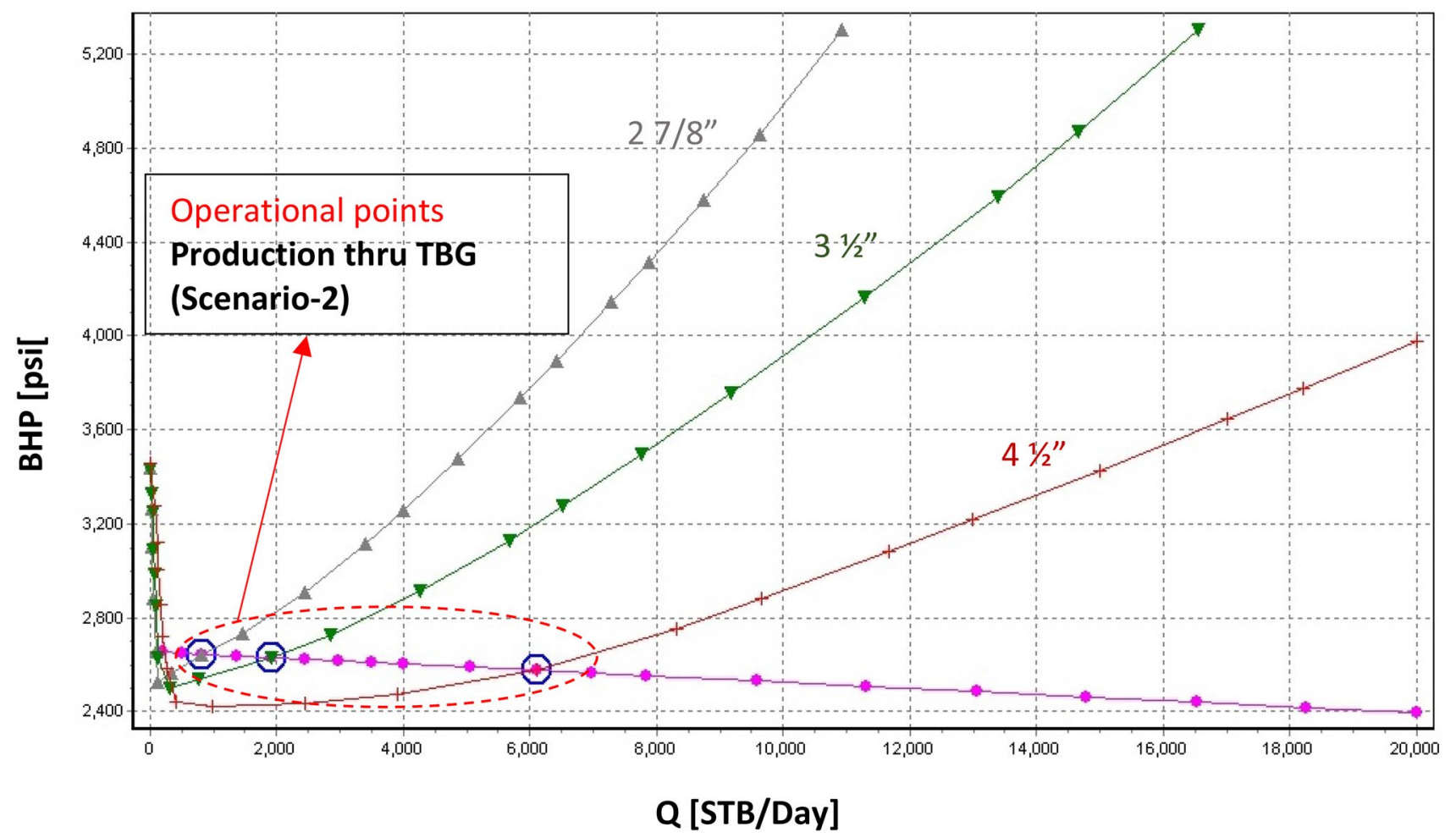

Fig. 6 Comparison of different tubing sizes in production through tubing. In tubing production, intersection of ascending/friction side of TPR with IPR must be considered as operational points. In the simulation, current tubing length was considered $(4921 \mathrm{ft} / 1500 \mathrm{~m})$. The selected wellhead pressure was 160 psig. Results of simulation show

tubing can be selected as optimal. Next, sensitivity analysis of surface wellhead pressure (WHP) versus production rate was performed for different tubing sizes for scenario-1 (Fig. 7) and for scenario-2 (Fig. 8). Simulation results show that production using $4 \frac{1}{2}$ " tubing (both through the annulus and tubing) provides the greatest WHP of all. At production rate of $1000 \mathrm{STB} / \mathrm{Day}$, WHP in production through annulus of $4 \frac{1}{2}$ " tubing (scenario-2) is the greatest of all sizes (187 psi, which is 35 psi greater than that of $27 / 8^{\prime \prime}$ one). At the same flow rate, WHP in production through $4 \frac{1 / 2}{2}$ tubing is the greatest of all ( $240 \mathrm{psi}$, which is 90 psi greater than that of $27 / 8$ " one). Combining results of both the nodal and sensitivity analyses shows that $4 \frac{1 / 2}{2}$ is the optimal size of tubing to be selected.

\section{Tubing length}

Following tubing diameter selection (4 1/2"), tubing length is optimized. Tubing length optimization and selection is accomplished using sensitivity analysis of wellhead pressures (WHP) versus production rates for different tubing lengths. Simulations were performed in two cases of

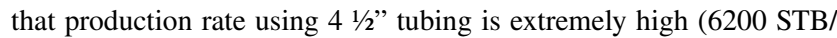
Day). However, increasing wellhead pressure (WHP), it is possible to limit production rate below the maximum permissible one; therefore, either $3 \frac{1 / 2}{2}$ " and $4 \frac{1 / 2}{2}$ " tubing could be considered as optimal

production through the annulus (Fig. 9) and through the tubing (Fig. 10). Results of the sensitivity analysis through the annulus show that WHP does not almost vary using different tubing sizes in the range of 800-2000 STB/Day. However, in production through tubing, WHP varies depending on tubing length. Using $7218 \mathrm{ft}(2200 \mathrm{~m})$ tubing, WHP is $290 \mathrm{psi}$ at production rate of $1000 \mathrm{STB} / \mathrm{Day}$ through the tubing. Using $5578 \mathrm{ft}(1700 \mathrm{~m})$ tubing, WHP is $270 \mathrm{psi}$ which is only 20 psi lower than that of $7218 \mathrm{ft}(2200 \mathrm{~m})$. This pressure difference is considered minimal; therefore, considering economic reasons, length of $5578 \mathrm{ft}(1700 \mathrm{~m})$ tubing is selected as the optimal one.

\section{Maximum tolerable water cuts}

With increasing well life, water cut (water percentage in the produced fluid) increases. Water cut indicates heavier fluid column in the well than with oil and gas. Therefore, increasing water cut causes reduction in surface WHP. This may lead to inadequate WHP required for production and finally production stop. It is important to know a maximum magnitude of water cut before which it is still possible to continue 


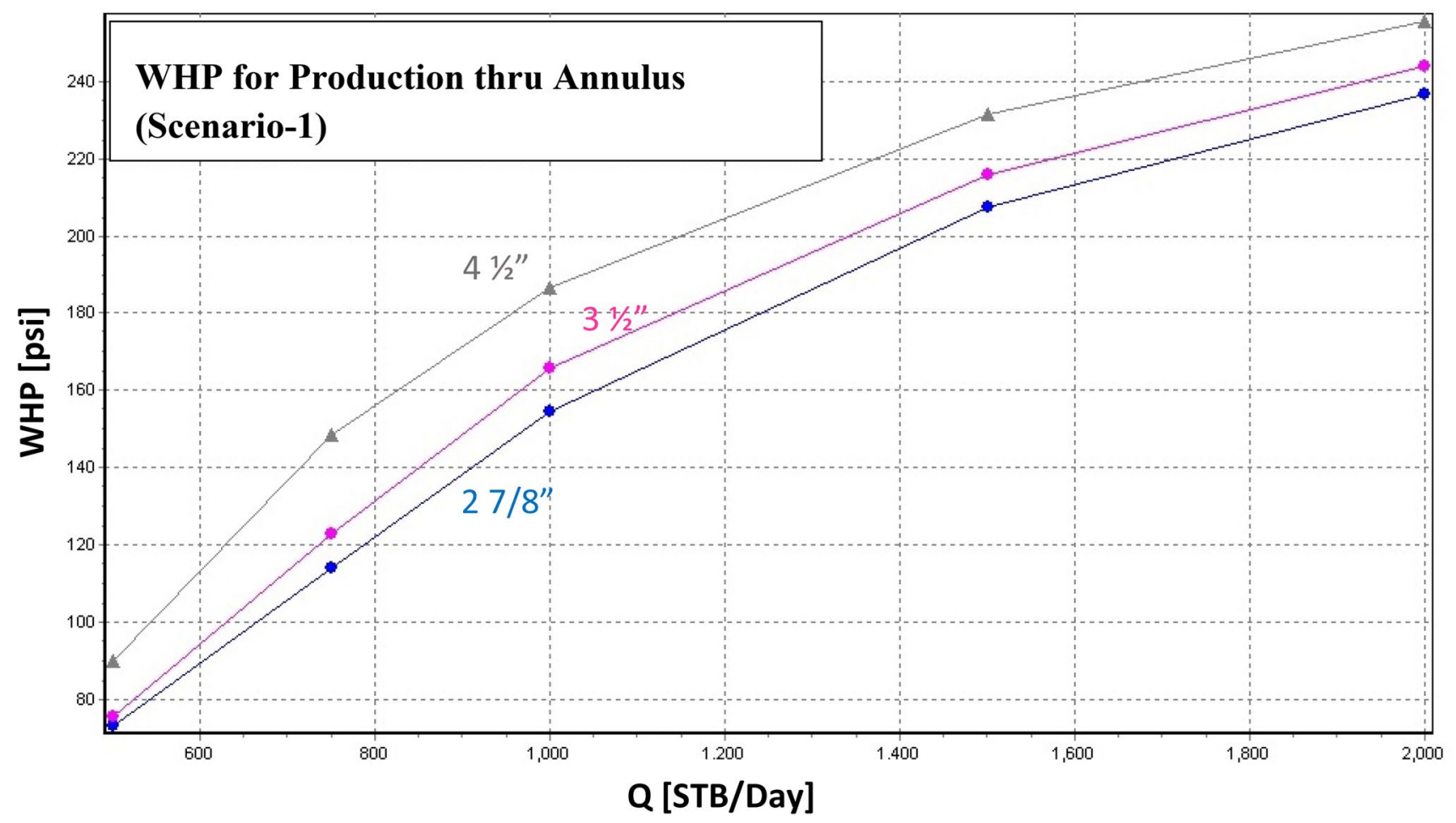

Fig. 7 Sensitivity analysis of different tubing diameter sizes in production through the annulus. At production rate of 1000 STB/Day, WHP in production through annulus of $4 \frac{1 / 2}{2}$ " tubing is the greatest of all (195 psi which is 33 psi greater than that of $27 / 8$ " one)

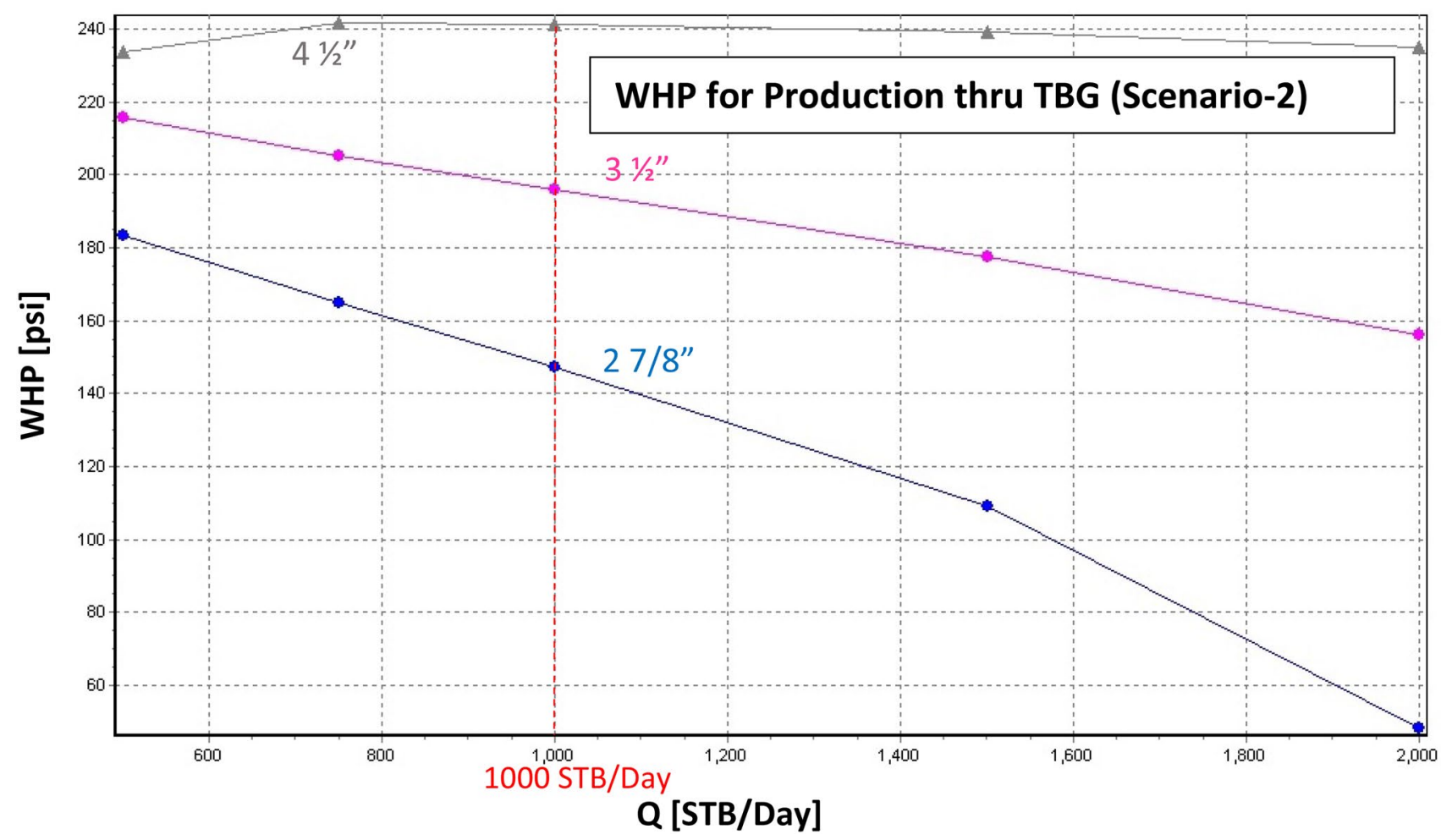

Fig. 8 Sensitivity analysis of different tubing diameter sizes in production through the tubing. At production rate of 1000 STB/Day, WHP in production through $4 \frac{1}{2}$ " tubing is the greatest of all (240 psi). This WHP is 90 psi greater than that of $27 / 8^{\prime \prime}$ one 
Fig. 9 Sensitivity analysis of wellhead pressures versus production rates for different tubing lengths (natural production through the annulus or scenario-1)
Fig. 10 Sensitivity analysis of wellhead pressures versus production rates for different tubing lengths (production through the tubing or scenario-2)
TBG Length Optimization Production thru Ann (Scenario-1)
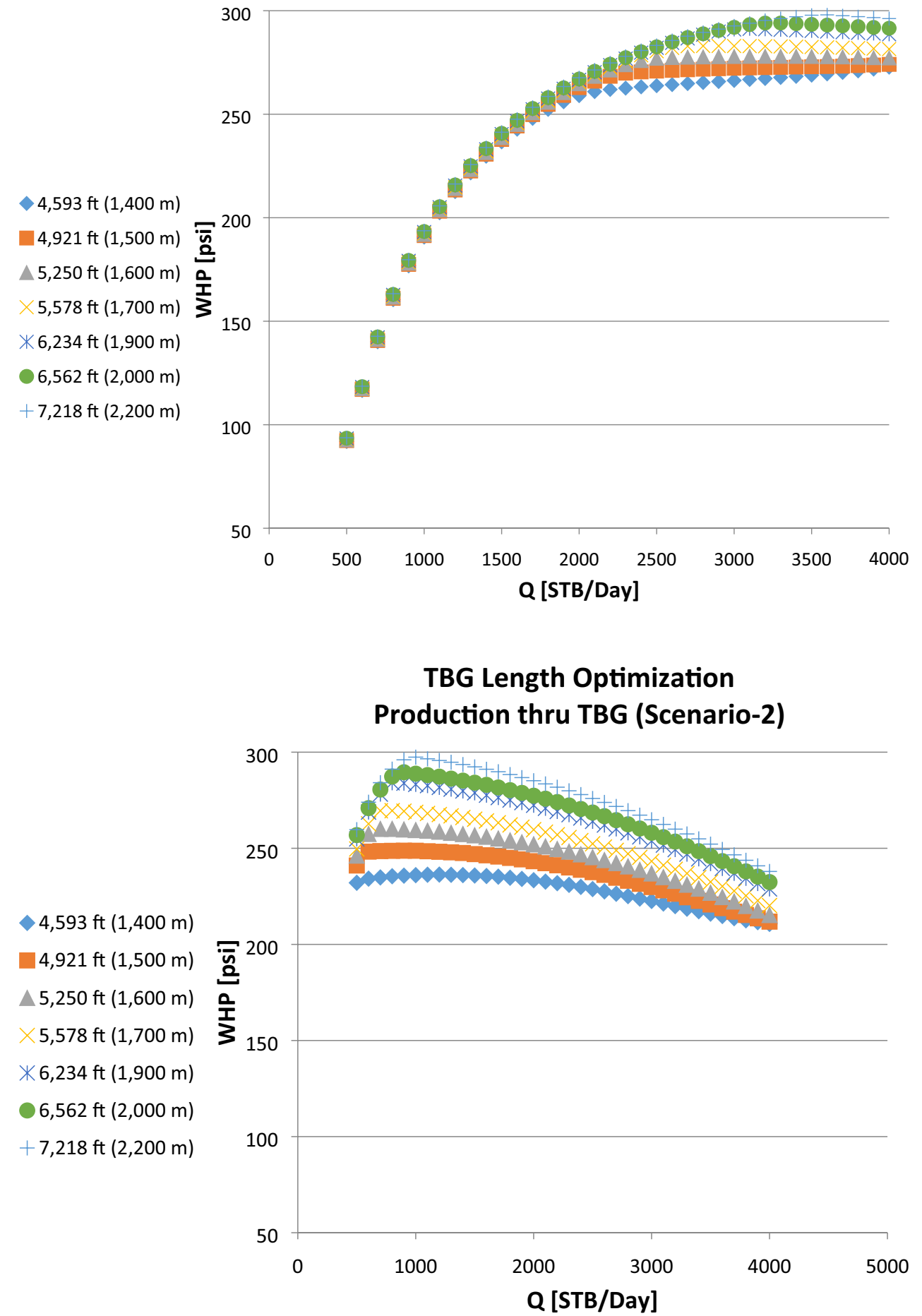

already selected tubing size. The optimal tubing diameter was already selected as $4 \frac{1}{2} 2$ ".

Figure 11 shows WHP versus maximum tolerable water cuts in natural production through annulus (scenario-1) and tubing (scenario-2) of different diameter sizes at production rate of $1000 \mathrm{STB} / \mathrm{Day}$. It shows that WHPs with sponding simulation results can also be used to confirm the 
Fig. 11 Maximum tolerable or allowable water cuts at specified wellhead pressures (WHPs) for production through annulus (scenario-1) and through tubing (scenario) of different sizes. The greatest maximum tolerable water cut is in production through 4 1/2" tubing (with value of $14 \%$ )

\section{Max Tolerable Water Cuts \\ (Scenario 1 vs 2)}

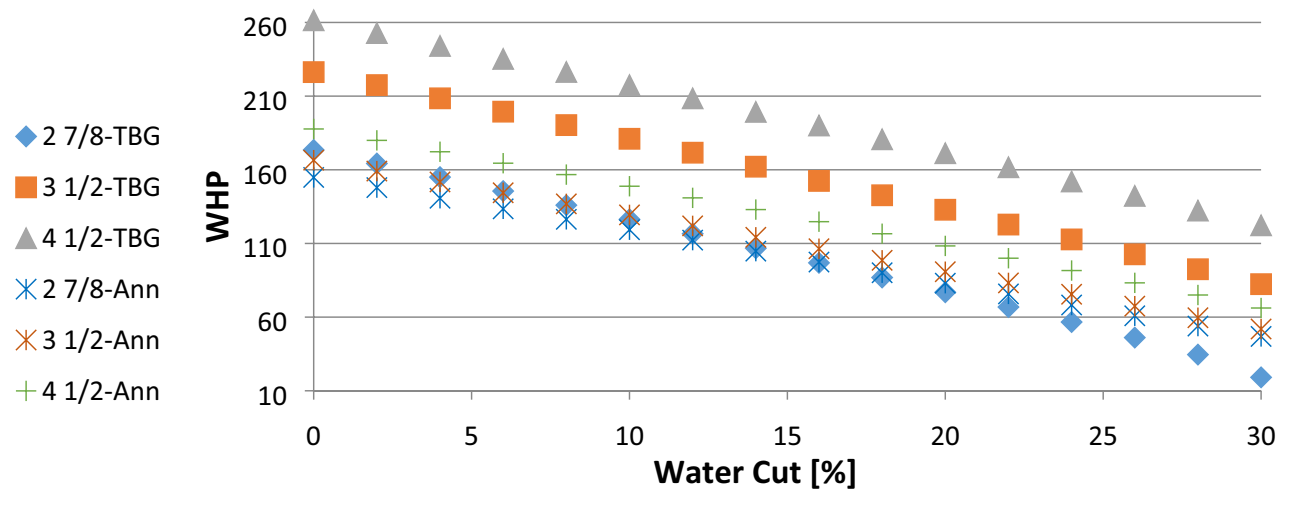

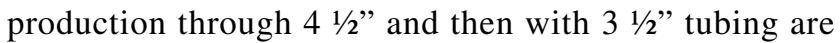
greater than those of annulus production. Therefore, $4 \frac{1 / 2}{2}$, tubing is the optimal as it gives the possibility with greatest maximum tolerable water cut of all (14\% water cut at WHP of $200 \mathrm{psi}$ ).

\section{Maximum allowable gas oil ratios}

With increasing well life, produced gas oil ratio (GOR) may increase particularly in gas-cap drive reservoirs, as is the case in this field. This increase may be possibly associated with a gas conning issue. Greater GOR indicates lighter fluid column in the well column than the case with lower GOR. Therefore, with GOR increasing, WHP increases. It may also causes gas handling issues at the surface (separator, etc.). Next, if GOR rises extremely high, it can cause extremely high WHP which may not be tolerable by surface equipment (pressure ratings). Therefore, it is important to know the maximum magnitude of GOR before which it is still possible to continue producing from a well. Care should be taken not to reach its maximum value; otherwise, production would halt. This

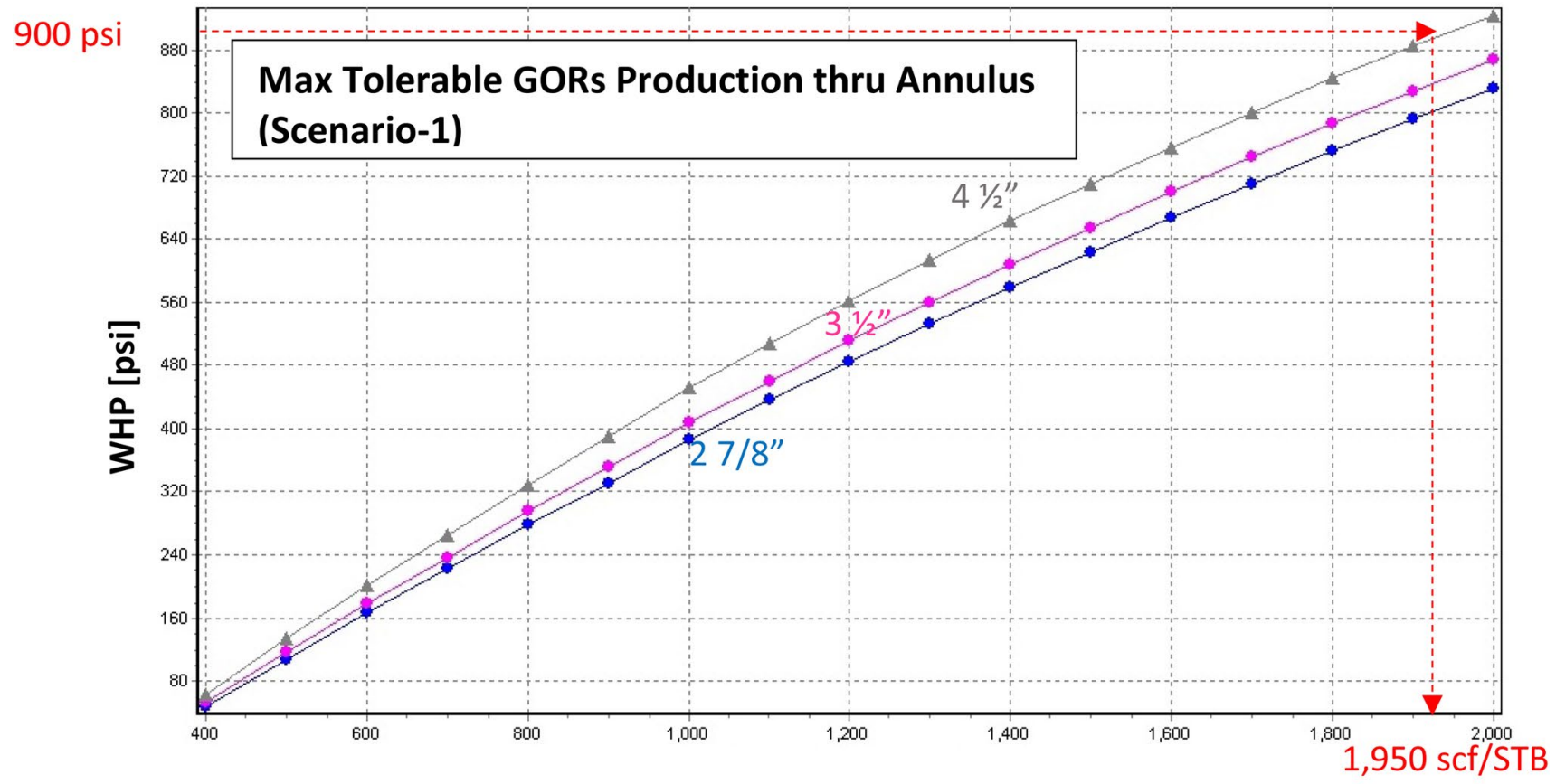

GOR [scf/STB]

Fig. 12 Maximum tolerable GORs at specified wellhead pressures (WHPs) for production through annulus (scenario-1) of different tubing sizes. The greatest maximum allowable GOR in production through $4 \frac{1 / 2}{2}$ " tubing is $1950 \mathrm{scf} / \mathrm{STB}$ 


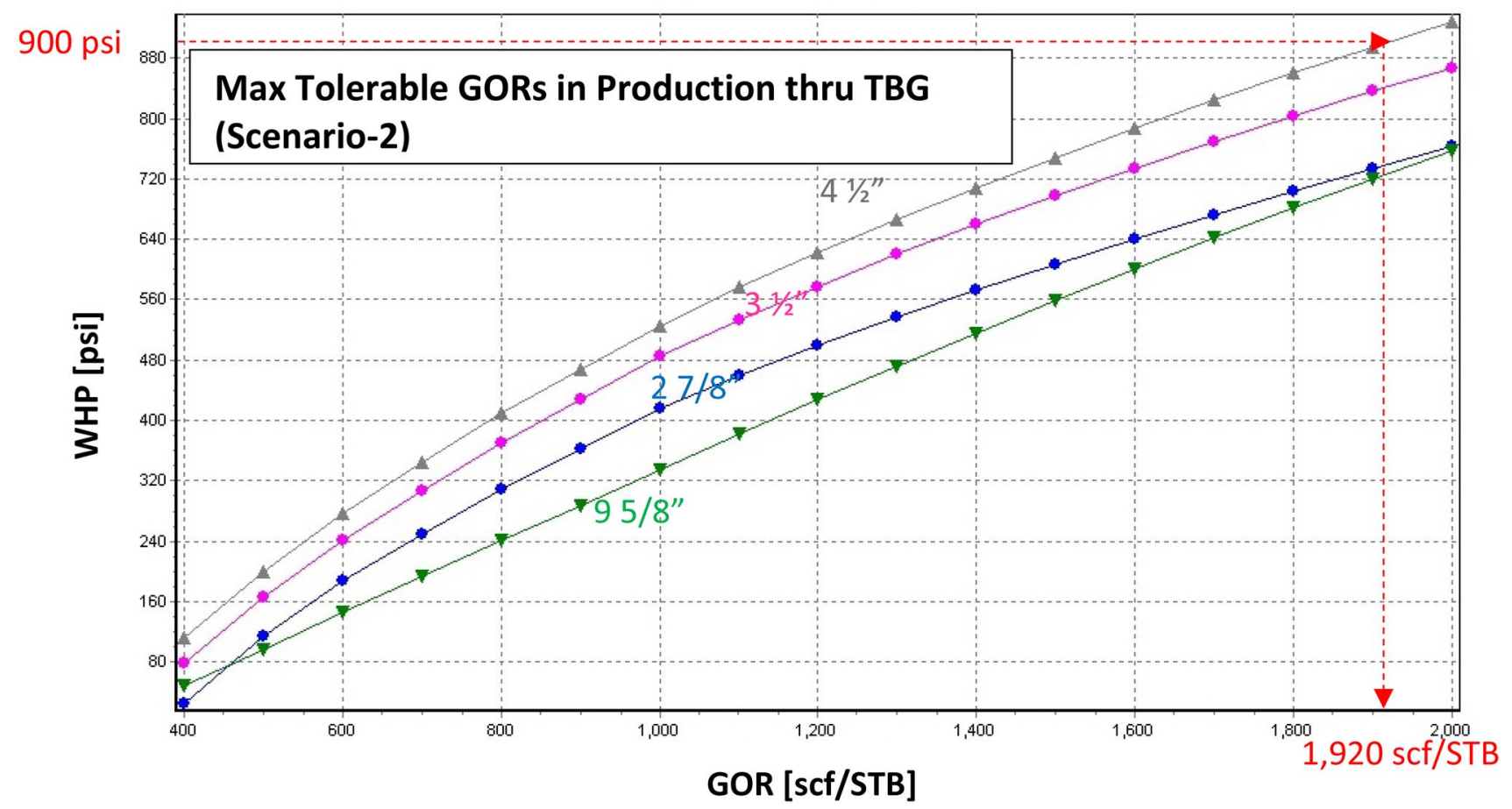

Fig. 13 Maximum tolerable GORs at specified wellhead pressures (WHPs) for production through tubing strings (scenario-2) of different sizes and also the casing (assuming no tubing in the hole). The greatest maximum allowable GOR in production through $4 \frac{1 / 2}{2}$ tubing is $1900 \mathrm{scf} / \mathrm{STB}$

maximum GOR is called maximum tolerable or allowable GOR. Because of its importance, this output is required from simulation results in addition to considering company policy. Based on company's policy in the studied field, WHP should not exceed 900 psi (not to exceed pressure rating of old surface wellhead Christmas tree facilities), and GOR should be maintained below $2000 \mathrm{scf} / \mathrm{STB}$ (to prevent gas handling issues).

Figure 12 shows WHP versus maximum tolerable GORs in production through annulus (scenario-1) of different tubing diameter sizes. It shows that again using the $4 \frac{1}{1} 2$ " tubing, it is possible to produce with greatest maximum tolerable GOR of all (1950 scf/STB). Figure 13 shows WHP versus maximum tolerable GORs in production through tubing (scenario-2) of different diameter sizes. The greatest maximum allowable GOR is for production through $4 \frac{1}{1} 2$ " tubing (with $1920 \mathrm{scf} / \mathrm{STB}$ ).

\section{Production through annulus versus tubing}

In natural production through the annulus or scenario-1, operational points are located on the declining side of the TPR, which pertains to its gravity (shown in Figs. 4, 5). However, in natural production through the tubing or scenario-2 (Fig. 6), operational points are located on the ascending side of the TPR which pertains to friction. In annulus production, the operational point is not as stable as production through tubing. By instability, it is meant that the IPR and TPR may lose their intersection point after some period of production time (i.e., no operational points). The period depends on the time when possible production problems would emerge. The problems include those adversely affecting the IPR (such as gas or water conning and different formation damage issues) and those affecting the TPR (e.g., flow assurance issues). It is noted that losing operational points may also occur in production through tubing after a while; however, it is considered less probable than in the case of production through the annulus (at least for $3 \frac{1 / 2}{2}$, and

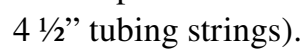

Figure 14 is the combination of Figs. 7 and 8 which shows WHP versus production rate for scenarios 1 and 2. Using this figure, it is inferred that production through tubing provides greater WHP compared with production through the annulus, in our desired production rate ranges. In production through the $4 \frac{1 / 2 "}{}$ " tubing, the greatest WHP is obtained. The desired rate of production in this well is up to $1500 \mathrm{STB} /$ Day. This is considered a positive indication of production improvement by virtue of production through tubing. This is important in this well with the depleted/low-pressure feeding reservoir. It is noted that the minimum WHP required in this well for natural production is 150 psi. Below this WHP, produced oil cannot reach itself to the nearest manifold where it is pressurized to reach the refinery. Therefore, a greater WHP is an advantage. At a reasonably high WHP 
Fig. 14 Comparison of WHP versus production rate $(\mathrm{Q})$ for production through the annulus (scenario-1) and through tubing (scenario-2). This figure is result of merging of Figures 7 and 8 . The dotted red vertical lines pertain to where curves of the two cases intersect and give the same WHP results

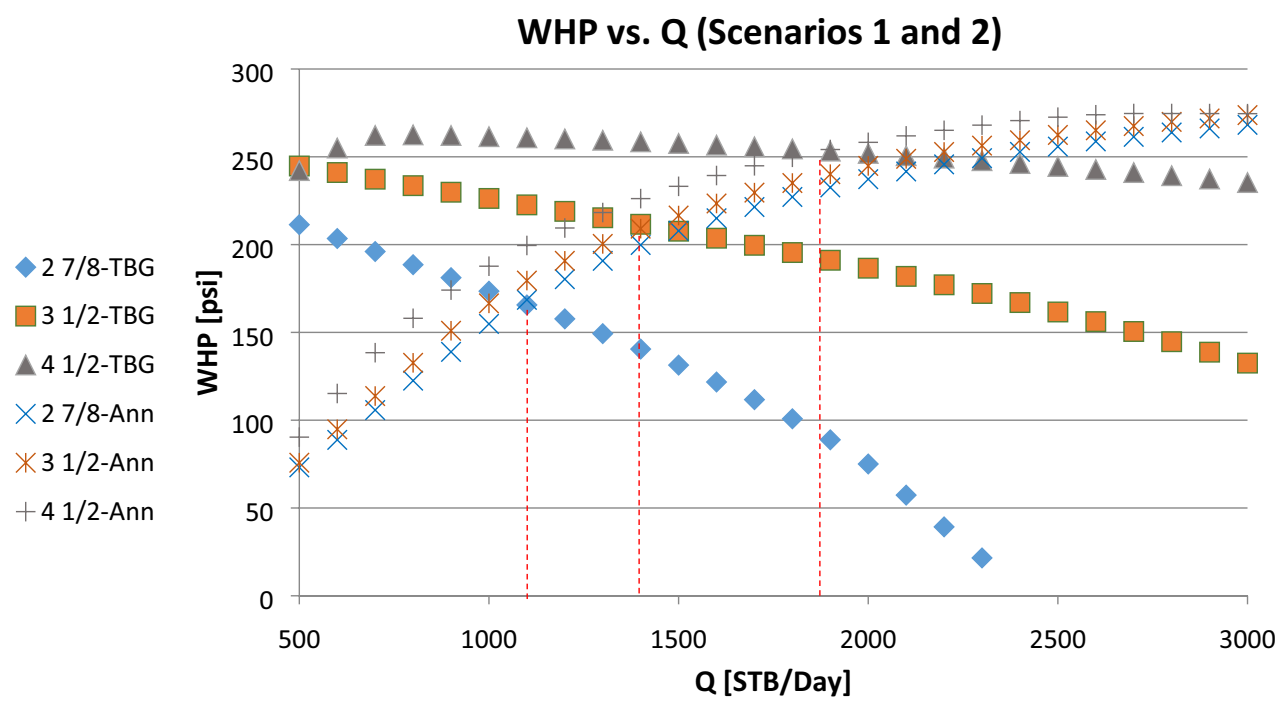

of 250 psi, Fig. 14 shows that the production rate through 4 $1 / 2$ " tubing is 1820 STB/Day which just slightly greater than the annulus production rate (1800 STB/Day). The rate where tubing production gives almost the same production rate as annulus production depends on the tubing size as shown in the same figure.

Next, using Fig. 11, it is inferred that maximum tolerable water cuts are greater in tubing production than in annulus production. As some drive in this field is believed to be provided by the aquifer, a high maximum tolerable water cut is considered an advantage. Finally, comparing Figs. 12, 13, it is inferred that maximum tolerable GORs in both tubing and annulus production cases do not differ considerably, especially for the optimal $4 \frac{1 / 2}{2}$ ' tubing.

\section{Artificial gas lift and optimization}

When it is not possible to produce naturally from a well or to improve production, artificial lift is an efficient way of reverting a well back to stream. To achieve this, an artificial lift method is "gas lift". In gas lift, gas is injected to be combined with oil; therefore, oil is lightened and can reach the surface. There are two methods of gas lift: 1 . non-standard gas lift and 2. standard gas lift. In non-standard gas lift, a simple kick-off tubing string (without any packer) is in the hole. Depending on production path (though annulus or tubing), there are two ways. If oil production is through the annulus, gas is injected through the tubing, and it enters the annulus from bottom of the string. Therefore, it lightens the oil in the annulus and allows its production to the surface. If oil production is through the tubing, gas injected through the annulus and lightens the oil in the tubing to be produced. In the standard gas lift method, the completion string is not merely a simple tubing string, but rather it is a string with side-pocket-mandrels (SPMs) and gas lift valves (GLVs) already installed there. Gas is injected through the annulus, and then it enters the tubing via GLVs (installed at several depths in the tubing string). Therefore, oil is lightened by gas and production becomes viable. The number and depths of GLVs in the tubing are designed by PIPESIM. Figure 15 shows differences in schematics of non-standard and standard gas lift cases.

Optimized gas lift parameters matter for optimal production conditions and success. To determine the optimal lift gas rate, the usual practice is to allocate the lift gas to a well according to a gas-lift performance curve (Nishikiori et al. 1989).

Based on Fig. 16 for production through annulus (scenario-3), the optimal rate of gas injection is $1 \mathrm{MMSCF} / \mathrm{Day}$ (with gas injection pressure of $1100 \mathrm{psi}$ ). As it is seen, at this rate of gas injection, using $4 \frac{1 / 2}{2}$ " tubing, the greatest production rate of 770 STB/Day can be obtained with WHP of 200 psi. Based on Fig. 17 for production through tubing (scenario-4), the optimal rate of gas injection is $0.4 \mathrm{MMSCF} /$ Day (with gas injection pressure of $1100 \mathrm{psi}$ ). As it is seen, at this rate of gas injection and WHP of 200 psi, using nonstandard gas lift (scenario-4), production rate of $830 \mathrm{STB} /$ Day can be obtained with $4 \frac{1}{2}$ " tubing. Using Table 3 , the standard gas lift can provide the production rate of $890 \mathrm{STB} /$ Day, which is $60 \mathrm{STB} / \mathrm{Day}$ greater than with non-standard gas lift. Using the results of gas lift modeling, it is inferred that artificial production through tubing using standard gas lift (scenario-5) is optimal because it delivers the greatest production rate. However, artificial production through annulus using non-standard gas lift (scenario-3) is the worst of gas lift cases for enhancing production. It is noted that in all gas lift scenarios, $4 \frac{1}{2}$ " size is considered the optimal tubing size as it contributes to the greatest production rates.

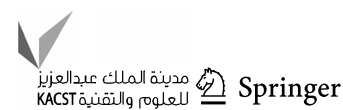


Fig. 15 a Schematics of nonstandard gas lift using a) a kickoff string with oil production through tubing (scenario-4) and b standard gas lift (scenario-5)

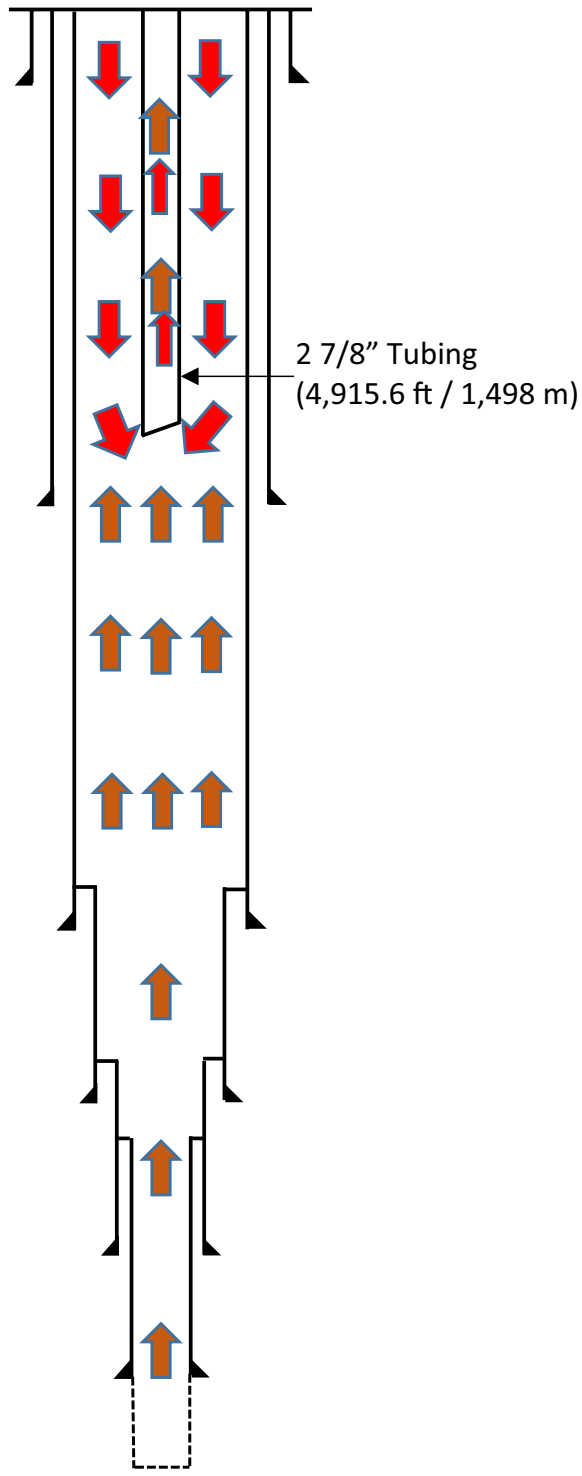

(a) Scenario-4

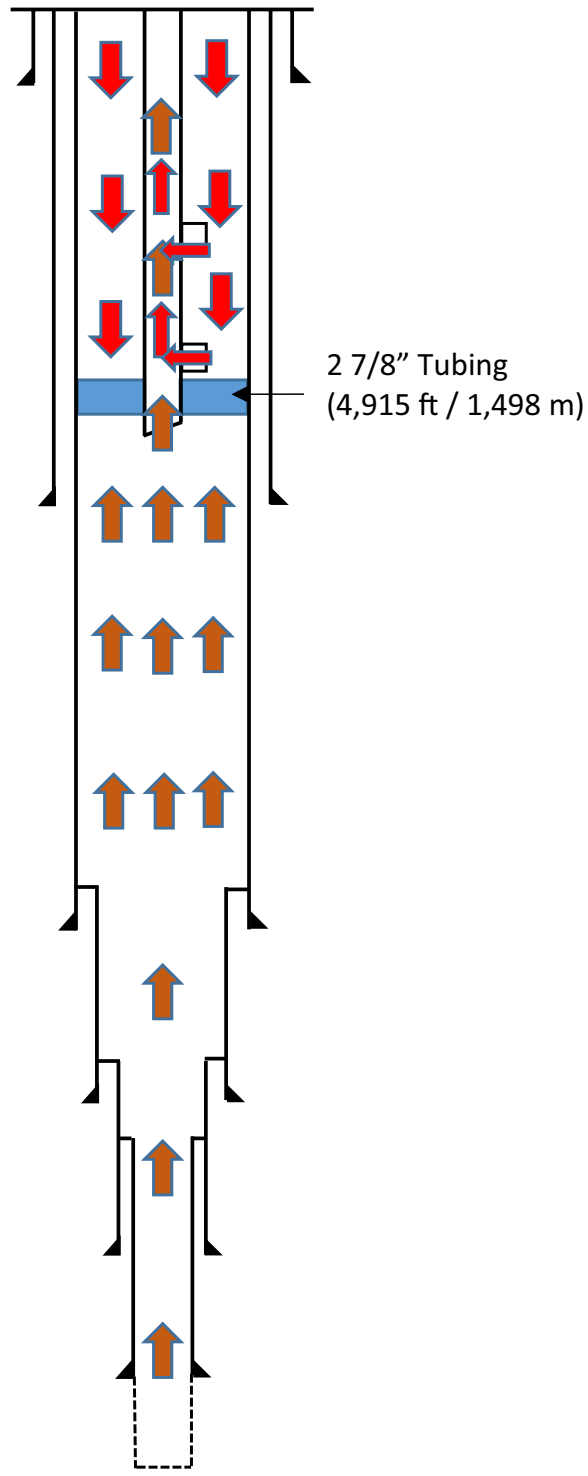

(b) Scenario-5
Next, by increasing gas injection pressure which causes WHP to increase as well, it is possible to increase the production rate. For example, using standard gas lift (scenario-5), at injection pressure of 1500 psi and WHP of $350 \mathrm{psi}$, the production rate can be increased to $990 \mathrm{STB} /$ Day (the greatest rate among other gas lift scenarios, see Table 3), whereas using non-standard gas lift (scenario-3), production rate is the lowest of all (880 STB/Day). Based on the same table, simulations show that natural rate of production through tubing (scenario-2) gave $1820 \mathrm{STB} /$ Day at WHP of only 200 psi. This production rate is above the recommended maximum allowable rate (1500 STB/ Day for this well) which can cause occurrence of gas and water conning after a while. Therefore, although gas lift production rates (for scenarios 3-5) are simulated lower than natural flow rates, it contributes to more stable production conditions. Stable production is one which would not induce conning issues. In brief, standard gas lift production is the optimal option.

\section{"Christmas trees" selection}

Wellheads are required to control pressure during drilling and production and serve as a point to suspend casing and tubing strings. It consists of several spools including casing head housing, casing head spool and tubing head spool. 


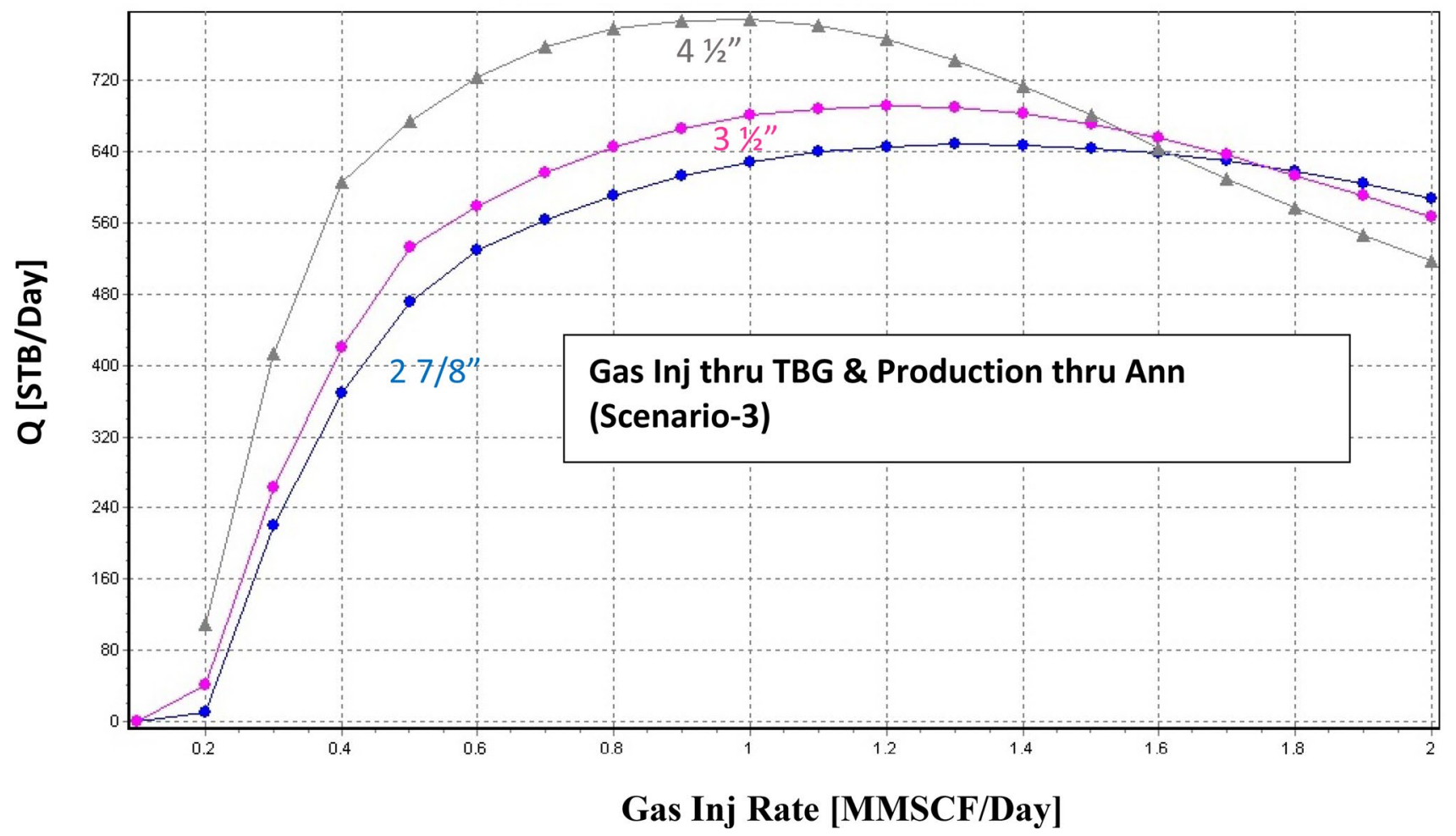

Fig. 16 Production rate versus gas injection rate showing effect of artificial gas lift with injection through the tubing and production through the annulus (scenario-3), with sensitivity analysis of different

However, the main purpose of Christmas tree is to control the flow of fluids during production.

It is noted that appropriate wellhead and Christmas tree selection is an essential part of any scenario shift in completion or production. Most Christmas trees currently installed on wells in the studied field (including the studied wells) allow shifting of from annulus to though tubing or vice versa. Therefore, using them, scenario-1-4 can be interchangeably shifted from one to another. This is doable just by using a crane to close and open valves; therefore, no drilling rigs or coiled tubing units are required and shift in the scenarios can be implemented in a cost-effective manner. However, to shift to scenario-5, a workover rig is required to replace the simple tubing with a new tubing equipped with side-pocket-mandrels (SPMs) where gas lift valves (GLVs) are seated and a packer at the bottom-end of the tubing.

For each of the five scenarios, almost the same wellhead is used, but the required Christmas tree and its components would be different. The current Christmas tree on the case study wells includes installation of a solid block and Christmas Cap (X. M. Cap) above the wellhead. It has a potential for interchanging production from annulus to tubing sizes. The gas injection pressure was $1100 \mathrm{psi}$. As the optimal injection rate of $1 \mathrm{MMSCF} / \mathrm{Day}$, using $4 \frac{1 / 2}{2}$ "tubing, the greatest production rate of 770 STB/Day is obtained with WHP of $200 \mathrm{psi}$

tubing or vice versa. Production through annulus is viable through line-1 (as shown in Fig. 18). If production through tubing is aimed, line- 2 can be used (same figure). This Christmas tree potentially allows applying a non-standard/ kick-off gas lift (in case it is required to improve production using gas lift). Injection and production lines for gas injection through the tubing and oil production through annulus are shown in Fig. 19. Injection and production lines for gas injection through the annulus and oil production through the tubing are shown in Fig. 20. However, this tree does not allow using a standard gas lift method where a packer is set at the bottom-end of the tubing (gas injection through the annulus and oil production through the tubing). To allow standard gas lift, completion mode is modified with a packer at the bottom end of the tubing and the appropriate Christmas tree. The tree would consist of: bottom and top master valves (gate valves), subsurface safety valve (2SV), swept bend, dipping valve and X. M. cap (see Fig. 21). 


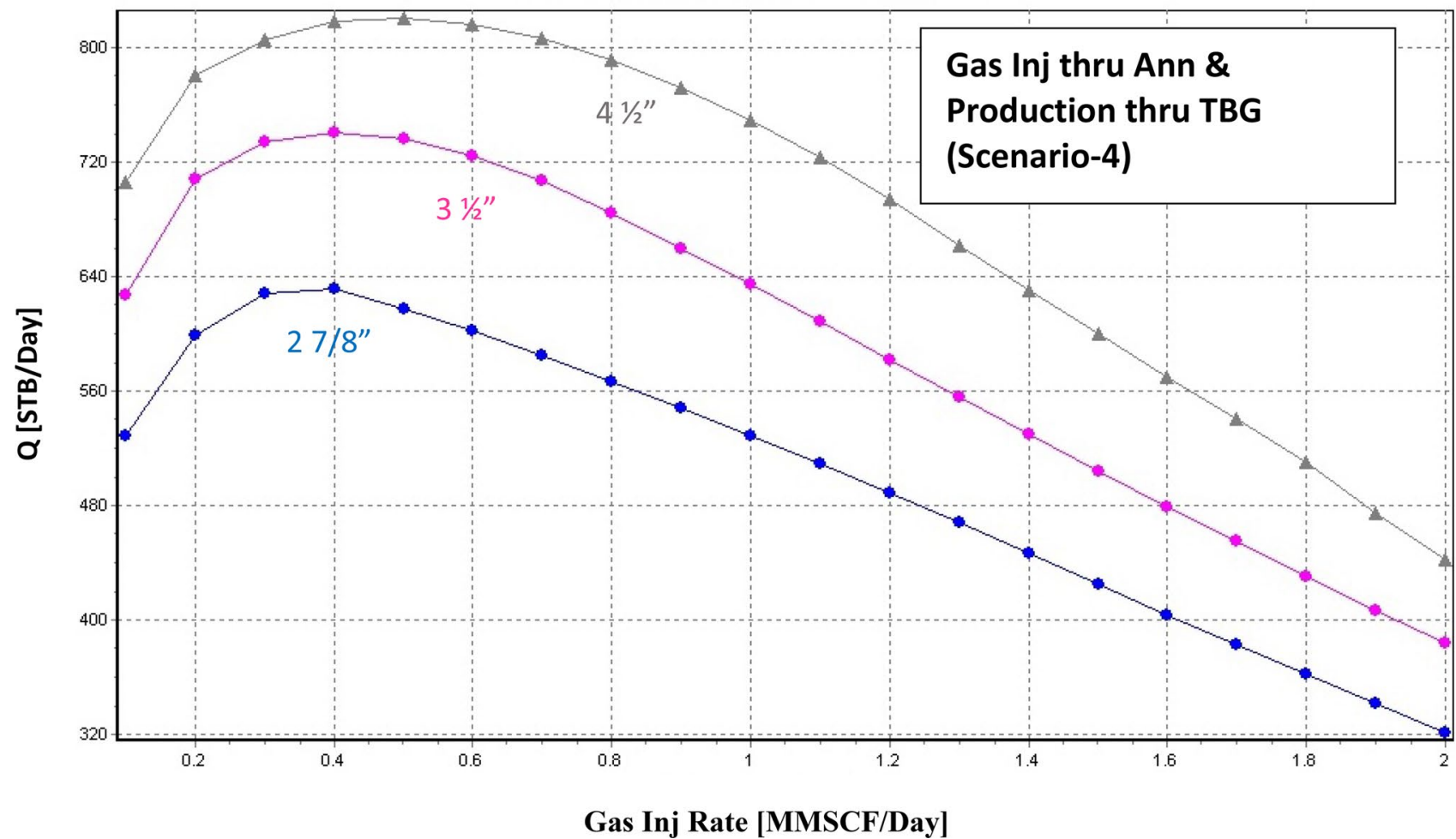

Fig. 17 Production rate versus gas injection rate showing effect of artificial gas lift with production through the tubing (scenario-4), with sensitivity analysis of different tubing sizes. The gas injection pres-

sure was $1100 \mathrm{psi}$. As the optimal injection rate of 0.4 MMSCF/Day, using $4 \frac{1}{2}$ " tubing, the greatest production rate of $830 \mathrm{STB} / \mathrm{Day}$ is obtained with WHP of $200 \mathrm{psi}$

Table 3 Comparison of rates of natural production through the tubing (scenario-2), non-standard gas lift with oil production through tubing (scenario-4) and standard gas lift (scenario-5)

\begin{tabular}{lllll}
\hline WHP [psi] & $\begin{array}{l}\text { Natural pro- } \\
\text { duction rate } \\
{[\text { STB/Day }]} \\
\text { (Scenario-2) }\end{array}$ & $\begin{array}{l}\text { Non-standard } \\
\text { (scenario-3) }\end{array}$ & $\begin{array}{l}\text { Non-standard } \\
\text { (scenario-4) }\end{array}$ & $\begin{array}{l}\text { Standard } \\
\text { (sce- } \\
\text { nario-5) }\end{array}$ \\
\hline 200 & $\begin{array}{l}1820\{\text { which } \\
\text { is above } \\
\text { maximum } \\
\text { allowable } \\
\text { flow rate } \\
\text { (scenario-2) }\end{array}$ & 770 & 830 & 890 \\
350 & zero & 880 & 940 & \\
\hline
\end{tabular}

\section{Case study II for field test verification}

To be able to rely on any simulation results, it is undoubtedly essential to verify or validate them using field pilot tests. This was done in another case study well.

The number of 12 WHP data was measured in the field at two production rates of 500 and 1000 STB/Day, for four scenarios (with natural and artificial gas lifts). Table 4 shows gas injection rates for different scenarios. In addition, Table 5 summarizes the field test results versus simulation results for WHP versus rate. The average absolute percent error (AAPE) of data for natural production scenarios was $23 \%$ and for artificial gas lift scenarios was $15 \%$. The AAPE for all the data was calculated as $18 \%$, which shows almost good matching, and validation of simulations results with field data was obtained.

Figure 22 shows measured field data versus simulation results for natural production through annulus (scenario-1) and through tubing (scenario-2). Figure 23 shows measured field data versus simulation results for artificial gas lift production through annulus (scenario-3) and through tubing (scenario-4) with choke size of 3/32". Figure 24 shows measured field data versus simulation results for artificial gas lift production through the annulus (scenario-3) and through tubing (scenario-4) with choke size of $1 / 8^{\prime \prime}$. A rather good validation of simulation results versus measured field data is observed in the figures. 


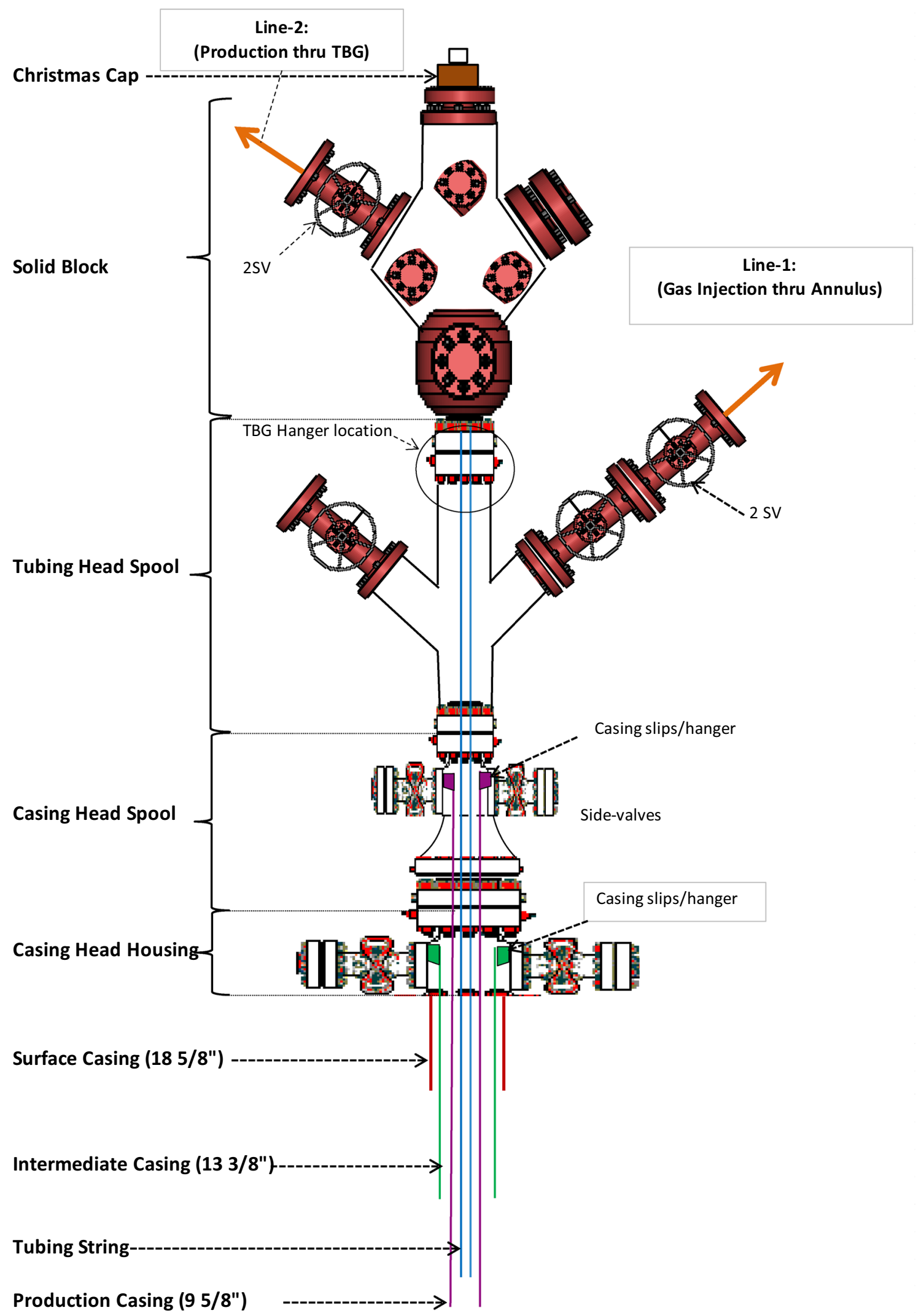

Fig. 18 Schematic of wellhead and Christmas tree with natural production either through the annulus (scenario-1) or tubing (scenario-2) 


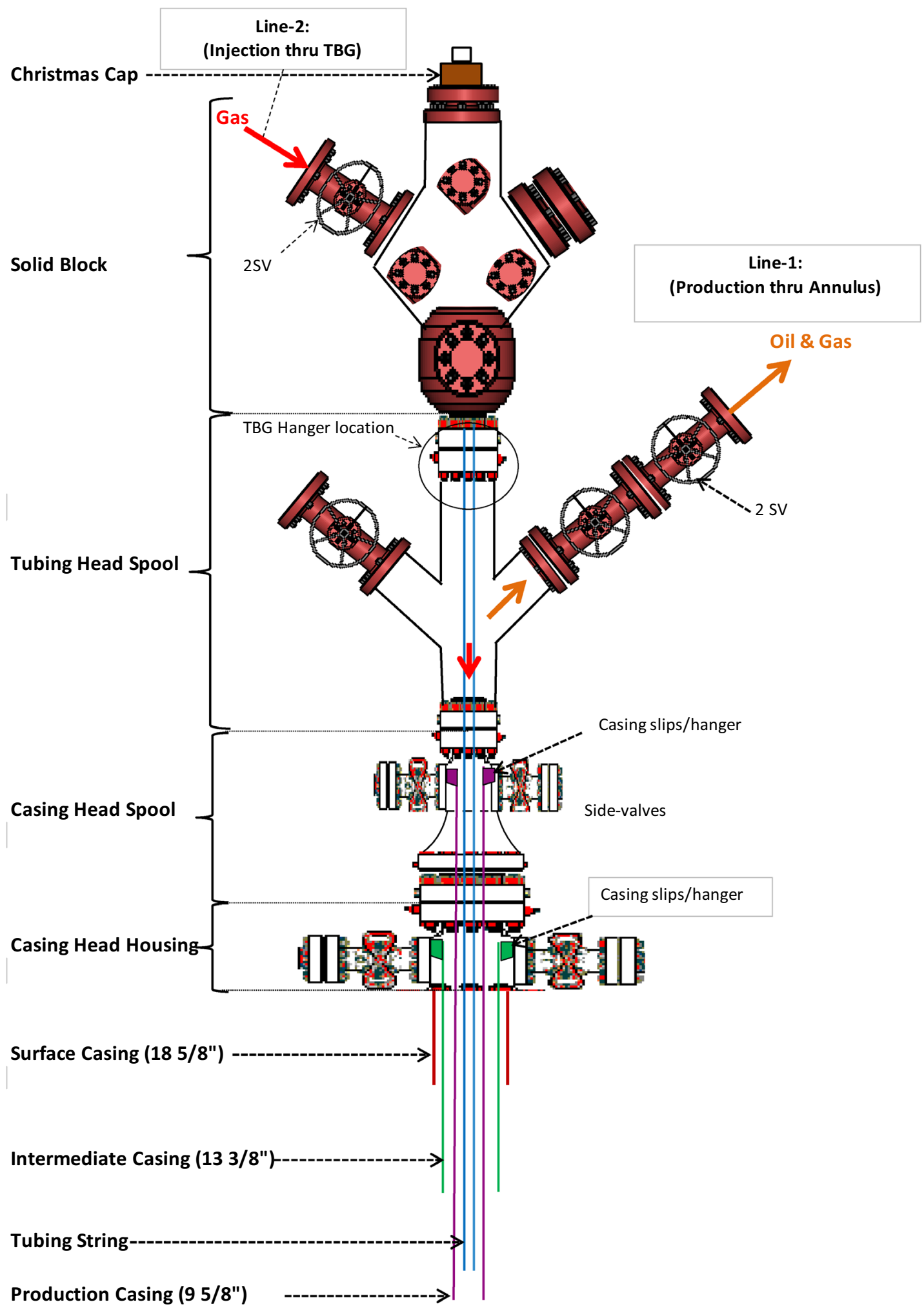

Fig. 19 Schematic of wellhead and Christmas tree with artificial gas lift production through the annulus (scenario-3) 


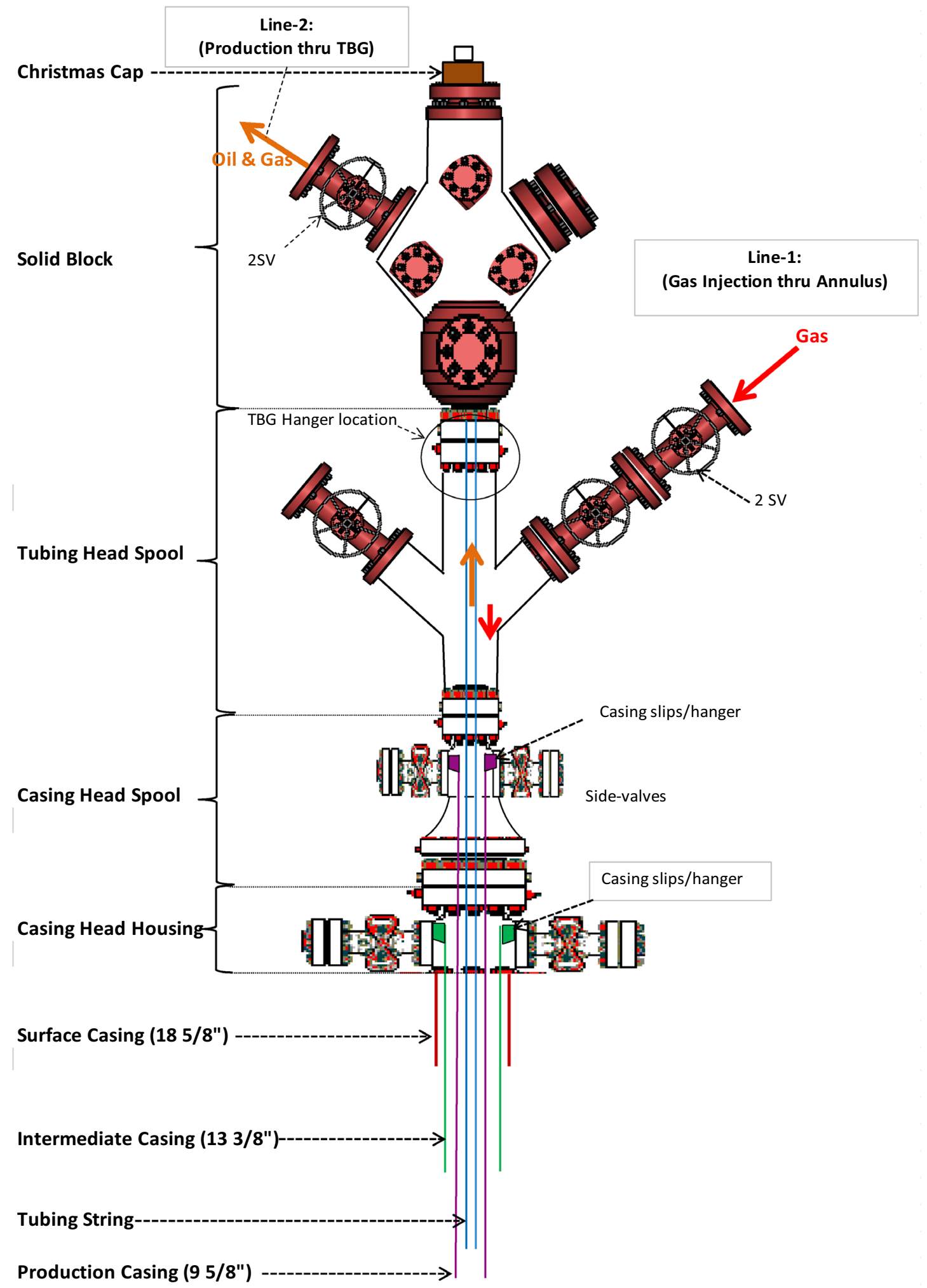

Fig. 20 Schematic of wellhead and Christmas tree with non-standard gas lift production through the tubing (scenario-4) 
2SV

2SV

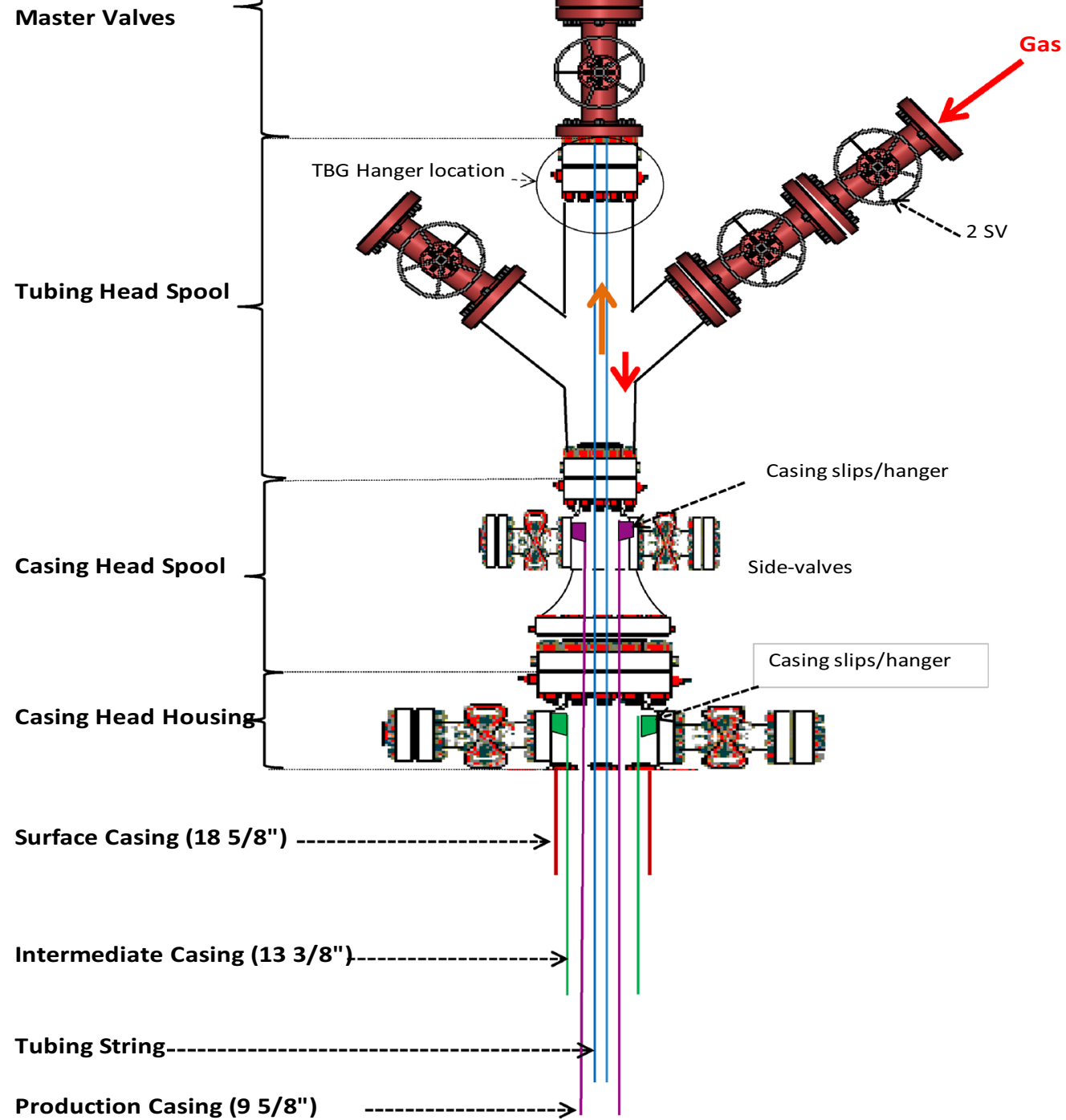

Fig. 21 Schematic of wellhead and Christmas tree for tubing production with standard gas lift (scenario-5) 
Table 4 Rates of gas injection for gas lift in different scenarios of production through the annulus (scenario-3) and tubing (scenario-4)

\begin{tabular}{|c|c|c|c|c|}
\hline \multirow[t]{3}{*}{ Q [STB/Day] } & \multicolumn{4}{|l|}{ Gas Inj rate } \\
\hline & \multicolumn{2}{|l|}{ Ann (Scenario-3) } & \multicolumn{2}{|l|}{ TBG (Scenario-4) } \\
\hline & 3/32" Choke & 1/8" Choke & 3/32" Choke & 1/8" Choke \\
\hline 500 & 0.47 MMSCF/Day & 0.56 MMSCF/Day & 0.43 MMSCF/Day & 0.47 MMSCF/Day \\
\hline 1000 & 0.38 MMSCF/Day & $0.52 \mathrm{MMSCF} / \mathrm{Day}$ & 0.37 MMSCF/Day & $0.52 \mathrm{MMSCF} / \mathrm{Day}$ \\
\hline
\end{tabular}

Table 5 Field test versus simulation results at two production rates of 500 and 1000 STB/day, with the average absolute percent errors (AAPEs). "sim." is abbreviation for simulation. The average absolute percent errors (AAPE) are given for all the data

\begin{tabular}{|c|c|c|c|c|c|c|}
\hline \multirow[t]{4}{*}{ Q [STB/Day] } & \multicolumn{6}{|l|}{ WHP [psi] } \\
\hline & \multicolumn{2}{|l|}{ Natural production } & \multicolumn{4}{|c|}{ Artificial gas lift } \\
\hline & \multirow[t]{2}{*}{ Ann (Scenario-1) } & \multirow[t]{2}{*}{$\overline{\text { TBG (Scenario-2) }}$} & \multicolumn{2}{|c|}{$\overline{\text { Ann (Scenario-3) }}$} & \multicolumn{2}{|c|}{ TBG (Scenario-4) } \\
\hline & & & 3/32" Choke & 1/8" Choke & 3/32" Choke & 1/8" Choke \\
\hline \multirow[t]{2}{*}{500} & 140 (field) & 320 (field) & 650 (field) & 720 (field) & 500 (field) & 540 (field) \\
\hline & $\begin{array}{l}112(\text { sim. }) \\
\mathrm{APE}=20 \%\end{array}$ & $\begin{array}{l}264(\operatorname{sim} .) \\
\mathrm{APE}=17 \%\end{array}$ & $\begin{array}{l}455(\operatorname{sim} .) \\
\mathrm{APE}=30 \%\end{array}$ & $\begin{array}{l}522(\text { sim. }) \\
\mathrm{APE}=27 \%\end{array}$ & $\begin{array}{l}580(\operatorname{sim} .) \\
\mathrm{APE}=16 \%\end{array}$ & $\begin{array}{l}518(\text { sim. }) \\
\mathrm{APE}=4 \%\end{array}$ \\
\hline \multirow[t]{3}{*}{1000} & 130 (field) & 200 (field) & 500 (field) & 580 (field) & 420 (field) & 480 (field) \\
\hline & $\begin{array}{l}182(\operatorname{sim} .) \\
\mathrm{APE}=40 \%\end{array}$ & $\begin{array}{l}233(\text { sim. }) \\
\text { APE }=16 \%\end{array}$ & $\begin{array}{l}465(\operatorname{sim}) \\
\quad \mathrm{APE}=7 \%\end{array}$ & $\begin{array}{l}512(\operatorname{sim} .) \\
\quad \mathrm{APE}=11 \%\end{array}$ & $\begin{array}{l}424(\operatorname{sim}) \\
\quad \mathrm{APE}=1 \%\end{array}$ & $\begin{array}{l}350(\operatorname{sim} .) \\
\text { APE }=27 \%\end{array}$ \\
\hline & $\mathrm{AAPE}=23 \%$ & & $\mathrm{AAPE}=15 \%$ & & & \\
\hline
\end{tabular}

Decimal points were not written for the errors

Fig. 22 Pilot field test results versus simulation (sim.) results for natural production through annulus (scenario-1) and through tubing (scenario-2). Good validation is observed

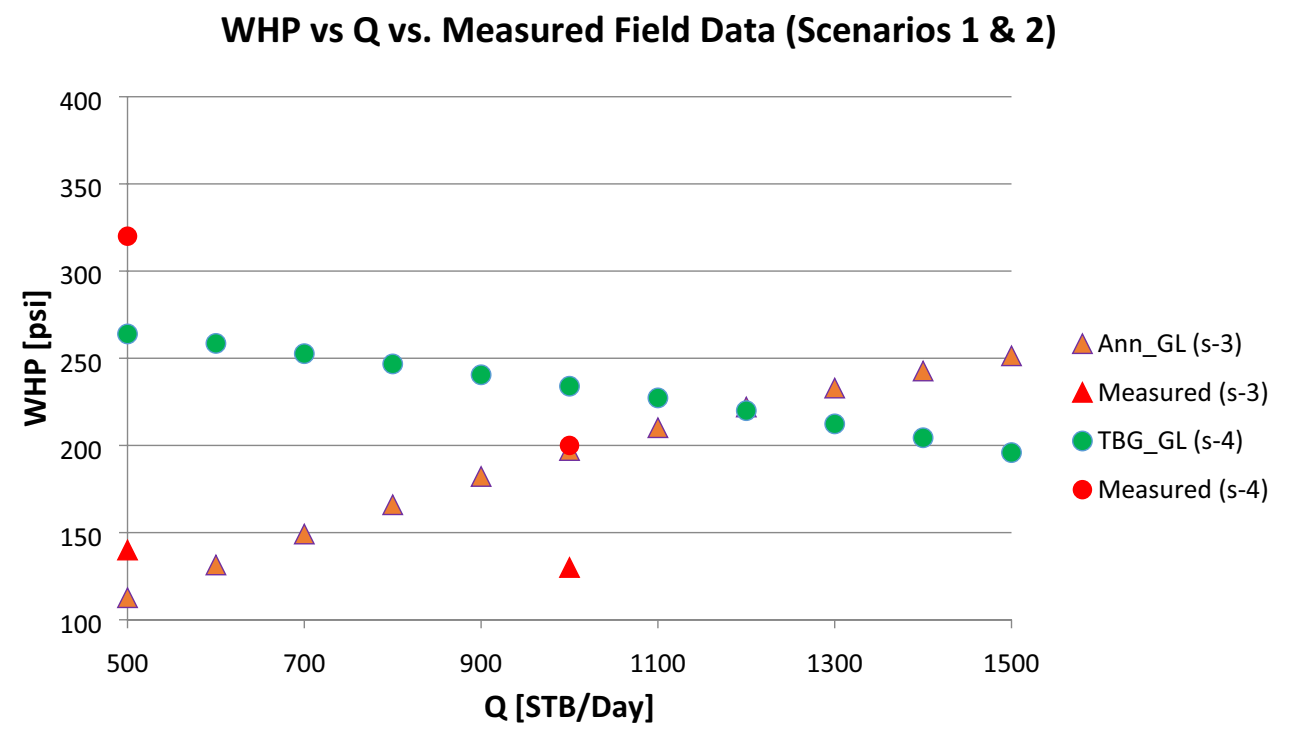

\section{Results and discussion}

In this part, the results of validated simulations of all the studied wells, validated by pilot first tests, are brought. Figures $25,26,27,28$ show a graphical deliverable of simulation results for production performance of the 11 studied wells. Tables 6, 7, 8 (in Appendix) give tabular presentations of the results with further details including the wellhead pressure (WHP) for each well.
The simulation results show that natural production rates through the tubing (scenario-2) are greater than through the annulus (scenario-1) in all the studied wells (Fig. 25). This increase was simulated equal to $800 \mathrm{STB} / \mathrm{Day}$ per well (from 1512 STB/Day to 2312 STB/Day). The WHP ranged from 200 to $300 \mathrm{psig}$, and the values are specified in Appendix for each well. Figure 26 shows that artificial production rates using non-standard gas lift with production through the tubing (scenario-4) are in the range of 917-1766 STB/ 
Fig. 23 Pilot field test results versus simulation (sim.) results for gas lift production through annulus (scenario-3) and through tubing (scenario-4). The selected choke size was $3 / 32$ ". Good validation is observed
WHP vs Q with Gas Lift vs. Measured Field Data (Scenarios 3 \& 4) 3/32" Choke

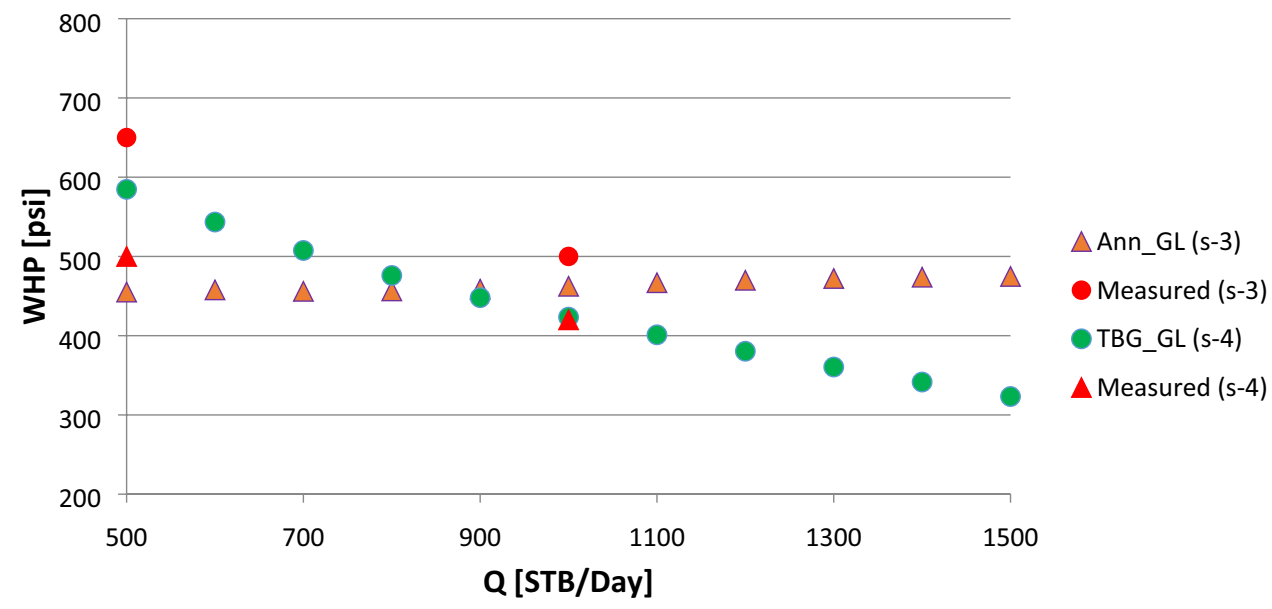

WHP vs $Q$ with Gas Lift vs. Measured Field Data (Scenarios 3 \& 4) 1/8" Choke

versus simulation (sim.) results for gas lift production through annulus (scenario-3) and through tubing (scenario-4). The selected choke size was $1 / 8^{\prime \prime}$. Good validation is observed

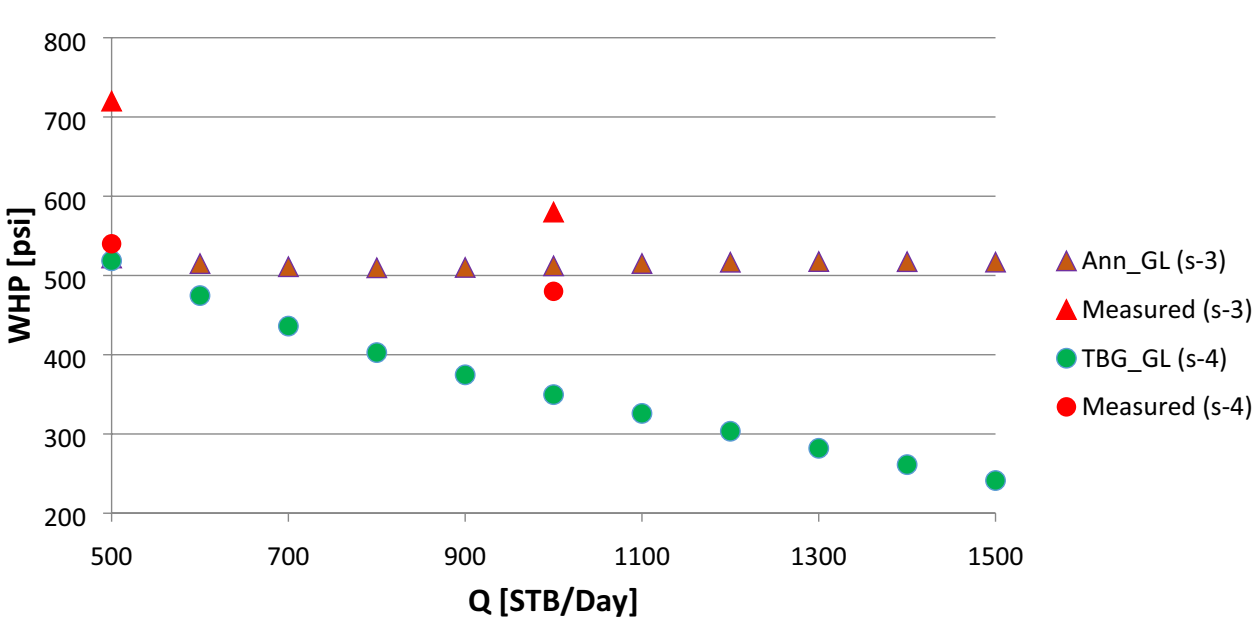

Day at WHP of $350 \mathrm{psig}$, whereas production rates through the annulus (scenario-3) are zero at this WHP. The average production rate increase from annulus to tubing production is $1185 \mathrm{STB} / \mathrm{Day}$.

Next, WHPs using standard gas lift through the tubing (scenario-5) are the greatest of all (with average of 366 psig) at production rate (Q) of 1000 STB/Day (see Fig. 27). In addition, natural production through the annulus (scenario-1), which is currently the case in most wells of the field, gives the lowest WHPs (with average of 204 psig). Natural production through tubing (scenario-2) gives $108 \mathrm{psi}$ (on average) greater WHP than that of scenario-1.

Next, the greatest maximum tolerable water cuts are obtained using standard gas lift through the tubing (scenario-5) with $29.5 \%$ on average at the production rate of
1000 STB/Day (see Fig. 28). The non-standard gas lift with production through tubing (scenario-4) is not shown in the figure for comparison because scenario- 5 gives better production conditions. The lowest maximum tolerable water cuts was zero for production through the annulus (scenario-1) which is currently the case in most wells of the field. Therefore, in scenario-1, if the well starts producing some water, natural production will inevitably stop. This is considered a really challenging risk for the production mode. The maximum tolerable GOR was found to be around 1900 scf/STB. Changing of scenarios does not have significant effect on the maximum tolerable GOR. To see the effect of changing of scenarios on this parameter, an example was given just for the first case study (see Figs. 12, 13). 
Overall, the above results indicate that natural production through annulus (scenario-1) is the worst production mode or scenario, whereas production through tubing (scenario-2) is optimal for wells which do not require gas lifting. However, for wells which cannot produce naturally and require gas lifting, the standard gas lift (scenario-5) is the optimal mode and is strongly recommended to improve their production conditions.

\section{Summary and conclusions}

Completion and production issues have reduced productivity of wells in South-West Iran and jeopardized sustainable production from the fields. An important measure to take conditions of existing wells under control and allow stable production is completion and production optimization. Five scenarios were investigated: natural production through annulus and tubing (scenario-1 and 2), artificial gas lift production through annulus (scenario-3), through tubing using non-standard gas lift (scenario-4) and using standard gas lift (scenario-5). Scenario-1 is currently the case in most wells of the field. To find the optimal scenario and completion/production parameters, simulations of 11 wells of the oilfield were carried out. Simulations included nodal and sensitivity analyses. The optimized parameters included wellhead pressures (WHPs), tubing dimensions, maximum tolerable water cuts and gas oil ratios (GORs) and artificial gas injection rate. Simulation results were validated by pilot field tests which showed rather good matching with final average absolute percent error (AAPE) of $18 \%$. The validated simulations showed that optimization of completion and production mode and parameters contributed largely to production improvement. Besides, the modified completion and production caused corrosion and mechanical damage to production casing which caused well integrity issues necessitating production halts for workover operations.

The following conclusions were made:

1. Hagedorn and Brown (HBR) correlation was determined as the best matching multiphase flow correlation with measured data for all the studied vertical wells.

2. Natural production through annulus (scenario-1) is the worst production mode or scenario, whereas production through tubing (scenario-2) was found optimal for wells which do not require gas lifting. However, for wells requiring gas lift, using standard gas lift (scenario-5) is the optimal mode and is strongly recommended.

3. Natural production rates in scenario-2 are greater than scenario-1 in all the studied wells (average $800 \mathrm{STB} /$ Day per well). Using artificial gas lift, the average pro- duction rate (per well) increase from annulus to tubing production was $1185 \mathrm{STB} / \mathrm{Day}$ at WHP of $350 \mathrm{psi}$.

4. WHPs using standard gas lift through the tubing (scenario-5) are the greatest of all (with average of 366 psig) at production rate of 1000 STB/Day. However, scenario-1 gave the lowest WHPs (average 204 psi per well). Production in scenario-2 gives 108 psi (on average) greater WHP than that of scenario-1.

5. The tubing diameter of $4 \frac{1 / 2}{2}$ "was found as optimal.

6. The optimal tubing length was determined 5250$5900 \mathrm{ft}(1600-1800 \mathrm{~m})$, with average of around $5577 \mathrm{ft}$ (1700 m).

7. The greatest maximum tolerable water cuts were found using standard gas lift through the tubing (scenario-5) with $29.5 \%$. The lowest maximum tolerable water cuts were zero for production through the annulus (scenario-1) which is currently the case in most wells of the field.

8. Maximum tolerable GOR was around $1900 \mathrm{scf} / \mathrm{STB}$. Changing of scenarios does not have significant effect on maximum tolerable GOR.

9. The optimal artificial gas injection rate of around 1 MMSCF/Day was determined for scenario-3, whereas a lower gas injection rate of around 0.4 MMSCF/Day was determined for scenario-5.

10. The main limitation of the modeling is its static nature (at the specified time when the simulation was conducted). In addition, the effect of superposition of production of each well was not seen on other wells. To consider the effect of superposition, it is recommended to consider a network modeling approach which is doable in commercial multiphase flow simulators.

Funding No funding was secured for this manuscript.

Open Access This article is licensed under a Creative Commons Attribution 4.0 International License, which permits use, sharing, adaptation, distribution and reproduction in any medium or format, as long as you give appropriate credit to the original author(s) and the source, provide a link to the Creative Commons licence, and indicate if changes were made. The images or other third party material in this article are included in the article's Creative Commons licence, unless indicated otherwise in a credit line to the material. If material is not included in the article's Creative Commons licence and your intended use is not permitted by statutory regulation or exceeds the permitted use, you will need to obtain permission directly from the copyright holder. To view a copy of this licence, visit http://creativecommons.org/licenses/by/4.0/.

\section{Appendix}

See Figs. 25, 26, 27, 28 and Tables 6, 7, 8 
Fig. 25 Natural production rates simulated for production through annulus (scenario-1, in yellow) and through tubing (scenario-2, in light green).

The tabular presentation of the figure and also the surface wellhead pressures (WHPs) are given in Table 6 (in Appendix)

Fig. 26 Production rates with artificial gas lift were found in simulation for two cases of production through the annulus (scenario-3, shown in brown) and through tubing (scenario-5, shown in dark green). The tabular presentation of the figures and the specified wellhead pressures for each well (WHPs) are given in Table 6 (in Appendix)
Fig. 27 Wellhead pressures (WHPs) were simulated in four scenarios: (s-1) natural production through the annulus yellow), (s-2) natural production through tubing (light green), (s-3) artificial gas lift production through the annulus (brown), and (s-5) artificial gas lift production through the tubing (dark green). Production was considered at a constant 1000 STB/Day for all the four scenarios. The tabular presentation of this figure is in Table 7 (in Appendix)
Natural Production Rates thru Ann vs. TBG

(Scenario 1 vs. 2)

(at WHP=200-300 psig)

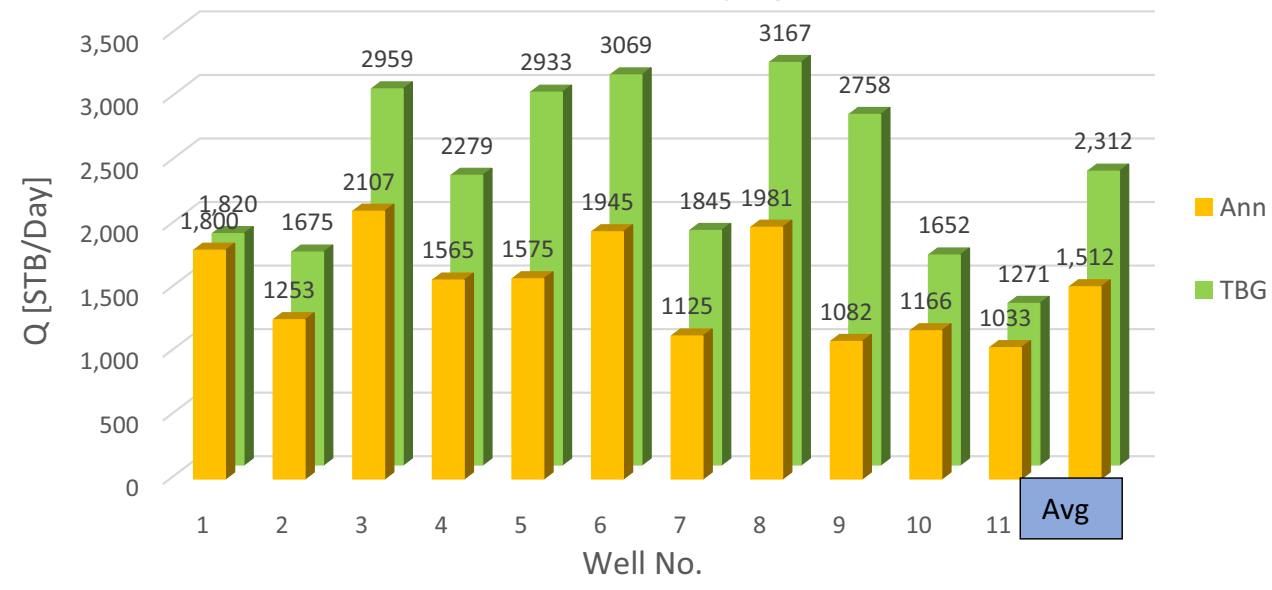

Production Rates with Artificial GL thru Ann vs. TBG

(Scenatio 3 vs. 5)

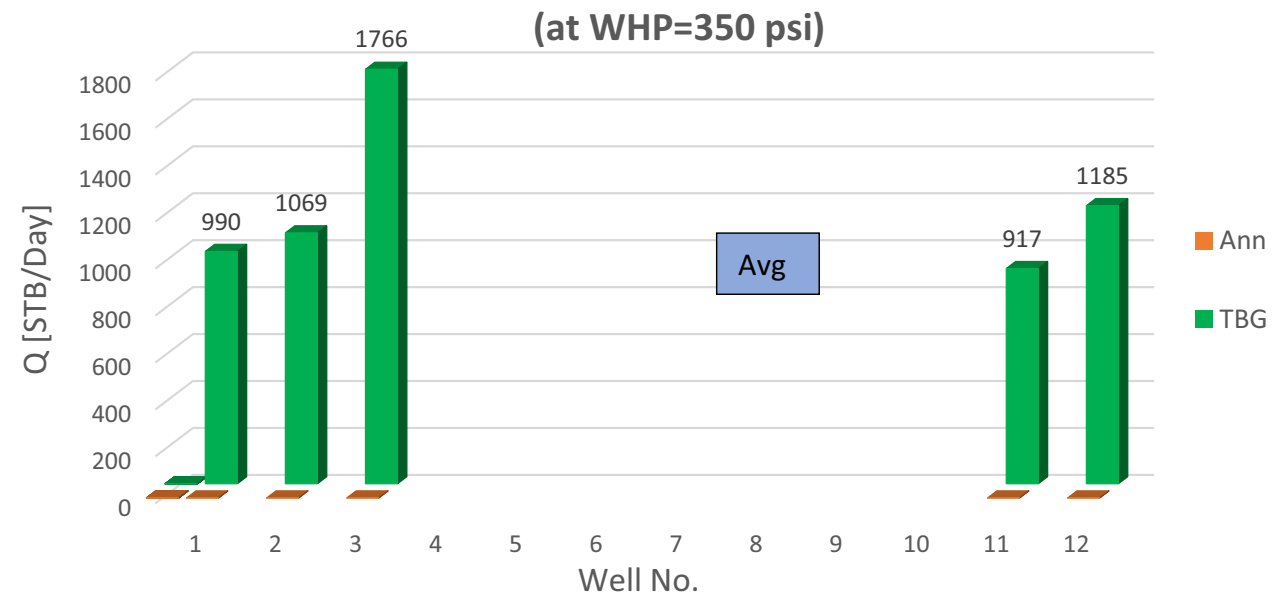

WHPs in Production thru Ann vs. TBG with \& without GL (Scenarios 1, 2, 3 \& 5)

(at $Q=1000$ STB/Day)

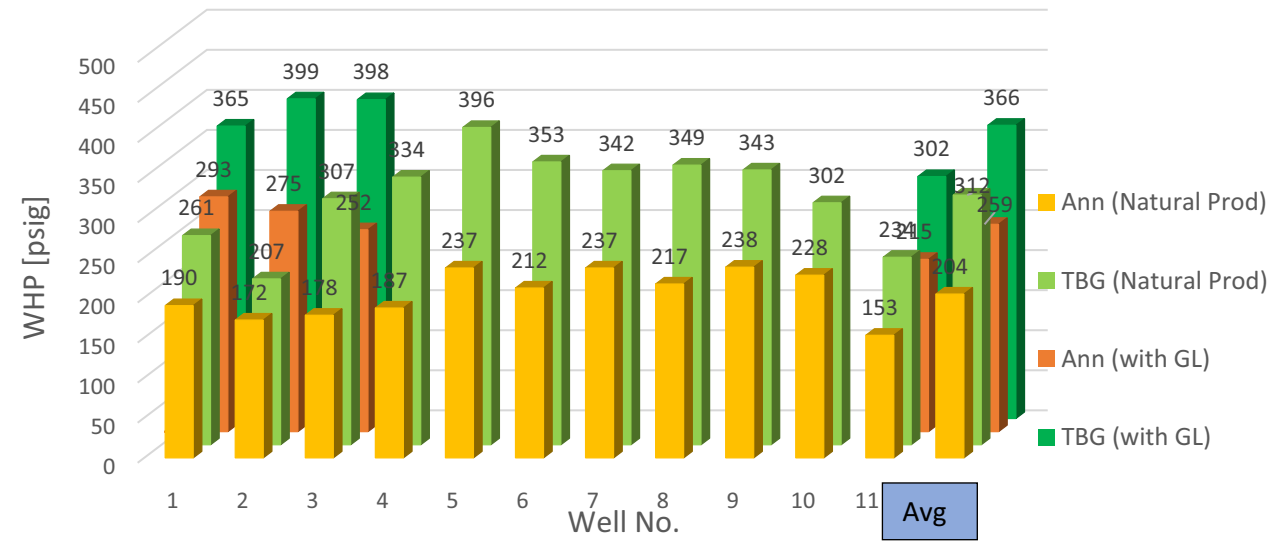



lated in four scenarios: (s-1) natural production through the annulus (yellow), (s-2) natural production through tubing (light green), (s-3) artificial gas lift production through the annulus (brown), and (s-5) artificial gas lift production through the tubing (dark green). Production was considered at a constant 1000 STB/Day for all the scenarios. The tabular presentation of this figure is in Table 7 (in Appendix)
Fig. 28 Water cuts were simu-

\section{Max Tolerable Water Cuts in Scenarios 1, 2, 3 \& 5 (at Q=1000 STB/Day)}

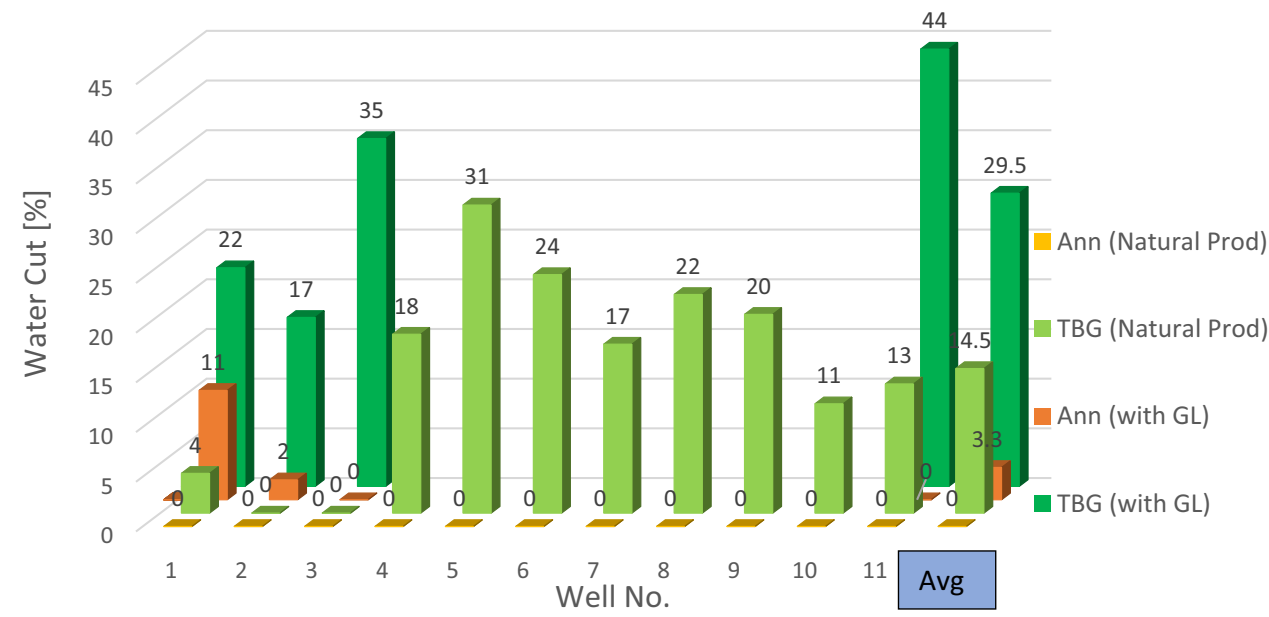

\begin{tabular}{|c|c|c|c|c|c|c|}
\hline \multirow[t]{2}{*}{ Well } & \multicolumn{3}{|c|}{ (a) Natural production rate [STB/Day] } & \multicolumn{3}{|c|}{$\begin{array}{l}\text { (b) Artificial gas lift production rate [STB/ } \\
\text { Day] }\end{array}$} \\
\hline & $\begin{array}{l}\text { thru Ann } \\
\text { (Scenario-1) }\end{array}$ & $\begin{array}{l}\text { thru TBG } \\
\text { (Scenario-2) }\end{array}$ & WHP [psi] & $\begin{array}{l}\text { thru Ann } \\
\text { (Scenario-3) }\end{array}$ & $\begin{array}{l}\text { thru TBG } \\
\text { (Scenario-5) }\end{array}$ & WHP [psi] \\
\hline 1 & 1800 & 1820 & 250 & zero & 990 & 350 \\
\hline 2 & 1253 & 1675 & 200 & zero & 1069 & 350 \\
\hline 3 & 2107 & 2959 & 250 & zero & 1766 & 350 \\
\hline 4 & 1565 & 2279 & 250 & & & \\
\hline 5 & 1575 & 2933 & 300 & & & \\
\hline 6 & 1945 & 3069 & 300 & & & \\
\hline 7 & 1125 & 1845 & 250 & & & \\
\hline 8 & 1981 & 3167 & 250 & & & \\
\hline 9 & 1082 & 2758 & 250 & zero & 917 & \\
\hline 10 & 1166 & 1652 & 250 & & & \\
\hline 11 & 1033 & 1271 & 200 & & & 300 \\
\hline Average & 1512 & 2312 & - & zero & 1185 & - \\
\hline
\end{tabular}

Table 7 Wellhead pressures (WHPs) in four scenarios: (s-1) natural production through the annulus, (s-2) natural production through tubing, (s-3) artificial gas lift production through the annulus, and (s-5) standard artificial gas lift production, at production flow rate of 1000 STB/Day. The rates of gas injection are given. The corresponding column chart illustration is given in the text (Fig. 27). "Ann" and "TBG" are abbreviations for annulus and tubing, respectively
Table 6 Natural and artificia through the annulus, (s-2) natural production through the gas lift production, at specified surface wellhead pressures for each well. The corresponding given in the text (Figs. 25 and abbreviations for annulus and tubing, respectively flow rates in four scenarios: production through the annulus,

\begin{tabular}{|c|c|c|c|c|c|}
\hline \multirow[t]{2}{*}{ Well } & \multicolumn{2}{|c|}{$\begin{array}{l}\text { (a) WHP with natural production } \\
\text { rate [psi] }\end{array}$} & \multicolumn{3}{|c|}{ (b) WHP with artificial gas lift production [psi] } \\
\hline & $\begin{array}{l}\text { thru annulus } \\
\text { (Scenario-1) }\end{array}$ & $\begin{array}{l}\text { thru TBG (Sce- } \\
\text { nario-2) }\end{array}$ & $\begin{array}{l}\text { thru Ann (Sce- } \\
\text { nario-3) }\end{array}$ & $\begin{array}{l}\text { thru TBG (Sce- } \\
\text { nario-5) }\end{array}$ & $\begin{array}{l}\text { Gas injection rate } \\
\text { [MMSCF/Day] }\end{array}$ \\
\hline 1 & 190 & 261 & 293 & 365 & 0.2 \\
\hline 2 & 172 & 207 & 275 & 399 & 0.2 \\
\hline 3 & 178 & 307 & 252 & 398 & 0.1 \\
\hline 4 & 187 & 334 & & & \\
\hline 5 & 237 & 396 & & & \\
\hline 6 & 212 & 353 & & & \\
\hline 7 & 237 & 342 & & & \\
\hline 8 & 217 & 349 & & & \\
\hline 9 & 238 & 343 & & & \\
\hline 10 & 228 & 302 & & & \\
\hline 11 & 153 & 234 & 215 & 302 & 0.1 \\
\hline Average & 204 & 312 & 259 & 366 & - \\
\hline
\end{tabular}


Table 8 Maximum tolerable water cuts in four scenarios: (s-1) natural production through the annulus, (s-2) natural production through the tubing, (s-3) artificial gas lift production through the annulus, and (s-5) artificial gas lift production through tubing, at production flow rate of 1000 STB/Day. The water cuts were simulated at wellhead pressure (WHP) of 250 psi. The corresponding column chart illustration is given in the text (Figure-28). "Ann" and "TBG" are abbreviations for annulus and tubing, respectively

\begin{tabular}{|c|c|c|c|c|}
\hline \multirow[t]{2}{*}{ Well } & \multicolumn{2}{|c|}{$\begin{array}{l}\text { (a) Water cut with natural } \\
\text { production [\%] }\end{array}$} & \multicolumn{2}{|c|}{$\begin{array}{l}\text { (b) Water cut with arti- } \\
\text { ficial gas lift production } \\
{[\%]}\end{array}$} \\
\hline & $\begin{array}{l}\text { thru annulus } \\
\text { (Scenario-1) }\end{array}$ & $\begin{array}{l}\text { thru TBG } \\
\text { (Scenario-2) }\end{array}$ & $\begin{array}{l}\text { thru Ann } \\
\text { (Scenario-3) }\end{array}$ & $\begin{array}{l}\text { thru TBG } \\
\text { (Sce- } \\
\text { nario-5) }\end{array}$ \\
\hline 1 & Zero & 4 & 11 & 22 \\
\hline 2 & zero & zero & 2 & 17 \\
\hline 3 & zero & zero & zero & 35 \\
\hline 4 & zero & 18 & & \\
\hline 5 & zero & 31 & & \\
\hline 6 & zero & 24 & & \\
\hline 7 & zero & 17 & & \\
\hline 8 & zero & 22 & & \\
\hline 9 & zero & 20 & & \\
\hline 10 & zero & 11 & & \\
\hline 11 & zero & 13 & zero & 44 \\
\hline Average & zero & 14.5 & 3.3 & 29.5 \\
\hline
\end{tabular}

\section{References}

Ansari, A.M., 1989. Comprehensive mechanistic model for pressure gradient, liquid holdup and flow pattern predictions. MSc Thesis, Tulsa, Ok: University of Tulsa

Ashena, R., Mehrara, R., Ghalambor, A. (2020) Well productivity improvement using radial jet drilling, presented at spe formation damage conference and exhibition, Lafayette, Louisiana, USA

Azin R, Chahshoori R, Osfouri S, Lak A, Sureshjani MH, Gerami S (2014) Integrated analysis of choke performance and flow behaviour in high-rate, deviated gas-condensate wells. Gas Process $2: 8-18$

Azin R, Sedaghati H, Fatehi R et al (2019) Production assessment of low production rate of well in a supergiant gas condensate reservoir: application of an integrated strategy. J Petrol Explor Prod Technol 9:543-560. https://doi.org/10.1007/s13202-018-0491-y

Beggs DH, Brill JP (1973) A study of two-phase flow in inclined pipes SPE-4007-PA. J Pet Technol 25(05):607-617. https://doi. org/10.2118/4007-PA

Beggs HD (2003) Production optimization using NODALTM analysis, 2nd edn. OGCI and Petroskills Publications, Tulsa, Oklahoma

Brown KE, Beggs HD (1978) The technology of artificial lift method, vol 1. Penn Well Public. Co., Tulsa, Oklahoma

Coroner SA, Outomuro Vazques M (1995). Using automation for optimizing production fields, SPE 29534, Presented at SPE Production Operations Symposium. Oklahoma City, Oklahoma. https:// doi.org/10.2118/29534-MS

Dmour H (2013) Optimization of well production system by NODAL analysis technique petroleum. Sci Technol 31:1109-1122
Duns, H. Jr. and Ross, N. C. J., 1963. Vertical flow of gas and liquid mixtures in wells. Proc., Sixth world Petroleum Congress, Frankfurt-am-Main, Germany 451

Gilbert WE (1954) Flowing and gas-lift well performance. American Petroleum Institute, Drilling and Production Practice, New York

Hagedorn AR, Brown KE (1965) Experimental study of pressure gradients occurring during continuous two-phase flow in small-diameter vertical conduits SPE-940-PA. J Pet Technol 17(04):475-484. https://doi.org/10.2118/940-PA

Hunter CM (1921) Oil Fields of Persia. Soc Pet Eng. https://doi. org/10.2118/921008-G

Jafarpour, H., Aghaei, H., Litvin, V., Ashena, R., 2021. Experimental optimization of a recently developed matrix acid stimulation technology in heterogeneous carbonate reservoirs, published online in journal of petroleum science and engineering, Vol. 196

Lockhart RW, Martinelli RC (1949) Proposed correlation of data for isothermal two-phase, two- component flow in pipes. Chem Eng Prog 45(1):39-48

Mukherjee H, Brill JP (1985) Pressure drop correlations for inclined two-phase flow. J Energy Resour Technol 1:1003-1008

Nasser, A. F. A., Ghareeb, M., \& Abdel Gawad, A., 2012. Production optimization in QPC fields. SPE 150667-MS, Presented at North Africa Technical Conference and Exhibition, 20-22 February, Cairo, Egypt. doi: https://doi.org/10.2118/150667-MS.

Nind TEW (1964) Principle of oil well production. McGraw-Hill, New York

Nishikiori, N., Redner, R. A., Doty, D. R., \& Schmidt, Z., 1989. An improved method for gas lift allocation optimization. SPE 19711-MS. Presented at SPE Annual Technical Conference and Exhibition, 8-11 October, San Antonio, Texas. doi: https://doi. org/10.2118/19711-MS

Pontiff, M. E., \& Boyer, B. E., 2005. Process optimization review. SPE 93939-MS. Presented at SPE/EPA/DOE Exploration and Production Environmental Conference, 7-9 March, Galveston, Texas. doi: https://doi.org/10.2118/93939-MS

Shadizadeh SR, Zoveidavianpoor M (2009) A successful experience in optimization of a production well in a Southern Iranian oil field. Iranian J Chem Eng (IAChE) 6(2):37-49

Shere, A. J., Roberts, Y. V. and Bakkevig, S., 2008. Online Production optimisation on Ekofisk. SPE 112130-MS. Presented at intelligent energy conference and exhibition, 25-27 February, Amsterdam, The Netherlands. doi: https://doi.org/10.2118/112130-MS

Soleimani M (2017) Well performance optimization for gas lift operation in a heterogeneous reservoir by fine zonation and different well type integration. J Nat Gas Sci Eng 40:277-287

Vogel, J. V., 1968. Inflow performance relationship for solution-gas drive wells. SPE-1476-PA, Published in JPT, Volume 20 (01), p. 83-92. doi:https://doi.org/10.2118/1476-PA

Wang, P., 2003. Development and applications of production optimization techniques for petroleum fields. a dissertation submitted to the department of petroleum engineering and the committee on graduate studies of Stanford University in partial fulfillment of the requirements for the degree of doctor of philosophy.

Publisher's Note Springer Nature remains neutral with regard to jurisdictional claims in published maps and institutional affiliations. 